\title{
Uzupełnienia i poprawki do listy porostów i grzybów naporostowych polskich Karpat
}

\author{
Urszula Bielczyk, Pawee Czarnota, \\ Dorota HollitZer-ZielińsKa i LuCYNA ŚLIWA
}

\begin{abstract}
Bielczyk, U., Czarnota, P., Hollitzer-Zielińska, D. And Śliwa, L. 2020. Additions and corrections to the checklist of Polish Carpathian lichens and lichenicolous fungi. Fragmenta Floristica et Geobotanica Polonica 27(2): 323-357. Kraków. e-ISSN 2449-8890, ISSN 1640-629X.

ABSTRACT: The list includes 241 taxa of lichen-forming fungi (lichens), 108 taxa of lichenicolous fungi and two lichenicolous myxomycetes about which records from the Polish Carpathians were reported after 2003, after the publication of checklists of lichens and lichenicolous fungi for the eastern and western part of this mountain range within the borders of Poland. For each species, its distribution in physiographical units is given with reference to the original bibliographic sources. It was shown that 46 species should be excluded from the list of lichens of the Polish Carpathians, due to incorrect identification, nomenclatural changes or recent taxonomic concepts.
\end{abstract}

KEY WORDS: Carpathian bibliography, checklist, lichen-forming-fungi, lichenicolous fungi, lichenicolous myxomycetes, Polish Carpathians, species diversity

U. Bielczyk (autor korespondencyjny), Instytut Biologii, Uniwersytet Pedagogiczny im. KEN, ul.Podchorażych 2,30-084 Kraków,Polska; e-mail: urszula.bielczyk@e.up.krakow.pl

P. Czarnota, Zakład Ekologii i Ochrony Środowiska, Kolegium Nauk Przyrodniczych, Uniwersytet Rzeszowski, ul. Zelwerowicza 4, 35-601 Rzeszów, Polska; Pracownia Naukowo-Edukacyjna Gorczańskiego Parku Narodowego, Poręba Wielka 590, 34-735 Niedźwiedź, Polska; e-mail: pczarnota1@gmail.com

D. Hollitzer-Zielińska, L. Śliwa, Zakład Lichenologii, Instytut Botaniki im. W. Szafera Polskiej Akademii Nauk, ul. Lubicz.46, 31-512 Kraków, Polska; e-mail: d.hollitzer@botany.pl, l.sliwa@ botany.pl

\begin{abstract}
WSTĘP
Karpaty są jednym z ważniejszych centrów różnorodności porostów w Europie i interesującym obiektem badań lichenologicznych, których wyniki rozproszone są w licznych i różnorodnych publikacjach. Na początku XXI w. ukazało się kilka opracowań podsumowujących te dokonania, w postaci zbiorczych wykazów gatunków (BIELCZYK 2003; KONDRATYUK i in. 2003; KoŚCIELNIAK \& KISZKA 2003, 2005; BIELCZYK i in. 2004; OleCH 2004; LiSICKÁ 2005). Od czasu tych publikacji, wiedza o porostach występujących w Karpatach znacznie się wzbogaciła. Przyczyniły się do tego kolejne badania terenowe i rewizje taksonomiczne
\end{abstract}


zdeponowanych w zielnikach zbiorów, które ujawniły nowe taksony i wskazały kolejne stanowiska porostów już wcześniej znanych z tego obszaru. Również postęp w badaniach grzybów naporostowych zaowocował wieloma nowymi doniesieniami.

Obecnie trwają zaawansowane prace nad listą porostów i grzybów naporostowych całego łuku Karpat, w których uczestniczy grupa lichenologów ze wszystkich państw karpackich. W związku z tym projektem poddana została krytycznej rewizji i aktualizacji także lista porostów i grzybów naporostowych polskich Karpat (BIELCZYK 2003; KoŚCIELNIAK \& KISZKA 2003), czego efektem jest prezentowany w niniejszej pracy wykaz 352 taksonów odnalezionych na tym obszarze po roku 2003 oraz wcześniej pominiętych. Osobne zestawienie zawiera 49 taksonów wykluczonych, które powinny być z niej usunięte ze względu na błędną identyfikację i zaistniałe w międzyczasie zmiany nomenklatorowe. Obecnie, po przeprowadzonych korektach, lista porostów i grzybów z nimi związanych w polskiej części Karpat liczy 1569 taksonów, w tym 1522 gatunki, 19 podgatunków i 28 odmian. Wśród tych uzupełniających aktualną listę, znalazły się gatunki opisane dla nauki m.in. na podstawie okazów odnalezionych w granicach polskich Karpat, np.: Bacidina mendax, B. pycnidiata, Caloplaca micromontana, C. microstepposa, Lecanora microloba, Lepraria jackii var. toensbergiana, Llimoniella catapyrenii, Micarea nowakii, M. soralifera, Umbilicaria maculata, Verrucaria humida, Zwackhiomyces peltigerae oraz wiele gatunków rzadkich w granicach swych zasięgów, podanych po raz pierwszy dla poszczególnych pasm karpackich, całych Karpat lub Polski.

\section{MATERIAE I METODY}

Informacje na temat występowania poszczególnych taksonów w polskich Karpatach uzyskano na podstawie analizy literatury lichenologicznej dotyczącej tego obszaru, szczególnie opublikowanej po roku 2003, rewizji materiałów zielnikowych zdeponowanych w herbariach KRAM, KRAP i GPN (w przypadku gatunków wątpliwych) i aktualizacji oznaczeń zgodnie z najnowszymi opracowaniami taksonomicznymi autorów polskich i zagranicznych.

Nomenklaturę taksonów przyjęto generalnie za MYCoBANK FUnGAL DATABASES (http://www.mycobank.org), za wyjątkiem Pyrenodesmia albolutescens i Biatorina albopruinosa, które według sugestii K. WILK pozostawiono w rodzaju Caloplaca. Przy niektórych gatunkach zamieszczono synonimy pod jakimi występują w materiałach źródłowych. Dla każdego taksonu podano rozmieszczenie w regionach fizyczno-geograficznych Karpat (KONDRACKI 1989) z odniesieniem do oryginalnych źródeł. Zamieszczony na końcu wykaz literatury jest uzupełnieniem pełnej bibliografii lichenologicznej dotyczącej polskich Karpat (por. BIELCZYK U. (red.) 2003).

\section{LISTA GATUNKÓW}

odnalezionych w polskich Karpatach po roku 2003 i nieuwzględnionych w pracach BIELCZYK (2003) oraz KośCIELNIAKA i KISZKI (2003). Zastosowane skróty: * - grzyby naporostowe; \# - śluzowce naporostowe.

"Abrothallus caerulescens Kotte

Gorce: KUKWA \& CZARNOTA (2006).

*Abrothallus peyritschii (Stein) Kotte

Tatry: Boberski (1886) jako Abrothallus smithii Tul., ReHMAN (1879) jako A. smithii. 
* Abrothallus santessonii (D. Hawksw.) A. Suija, D. Hawksw. \& Pérez-Ort.

Syn: Vouauxiomyces santessonii D. Hawksw.

Tatry Zachodnie: KuKWA \& JABŁOŃSKA (2008).

Absconditella pauxilla Vězda \& Vivant

Tatry Zachodnie: CZARNOTA (2012); Beskid Niski: BIELCZYK i in. (2016).

Acarospora intermedia $\mathrm{H}$. Magn.

Gorce: CZARNOTA i in. (2005).

Adelolecia kolaensis (Nyl.) Hertel \& Rambold

Syn: Lecidea cf. conferenda Nyl.

Gorce: CZARNOTA \& WoJNAROWICZ (2008).

Agonimia flabelliformis Halda, Czarnota \& Guzow-Krzem.

Tatry Zachodnie: CZARnota (2012).

Anisomeridium polypori (Ellis \& Everh.) M.E. Barr

Pogórze Wiśnickie: Śliwa (2006); Beskid Żywiecki: Czarnota \& WęGrzyn (2012); Gorce: CZarnota \& Coppins (2006), CZarnota \& Wojnarowicz (2008); Beskid Niski: BielczyK i in. (2016); Rów Podtatrzański: Śliwa (2010); Bieszczady Zachodnie: KoŚcIELNIAK (2013).

* Arthonia almquistii Vain.

Tatry Wysokie: KuKwa \& Flakus (2009).

*Arthonia digitatae Hafellner

Beskid Żywiecki: Kunwa i in. (2010); Gorce: KuKwa i in. (2010); Tatry Zachodnie: CZarnota (2012); Tatry Wysokie: CZARNota (2012).

* Arthonia peltigerina (Almq.) H. Olivier

Tatry Wysokie: KUKWA \& FlaKUS (2009).

* Arthrorhaphis aeruginosa R. Sant. \& Tønsberg

Beskid Makowski: KuKwa \& KowalewsKa (2007); Beskid Żywiecki: KuKwa \& KowalewsKa (2007), KuKwa i in. (2010); Beskid Wyspowy: KuKwa \& CZARnota (2006); Gorce: KuKWA \& CZARnota (2006), Kukwa i in. (2010); Beskid Sądecki: Kukwa \& Czarnota (2006); Beskid Niski: Bielczyk i in. (2016); Tatry Zachodnie: KUKWA \& CZARNOTA (2006).

Aspicilia polychroma var. rubrireagens Asta \& Cl. Roux

Tatry Wysokie: FlaKus $(2007,2014)$.

Athallia cerinella (Nyl.) Arup, Frödén \& Søchting

Syn.: Caloplaca cerinella (Nyl.) Flagey

Beskid Niski: BIELCZYK i in. (2016).

Athallia pyracea (Ach.) Arup, Frödén \& Søchting

Syn.: Caloplaca pyracea (Ach.) Zwackh

Bieszczady Zachodnie: KAPEK (2014).

Uwaga: Gatunek prawdopodobnie częsty w polskich Karpatach, ale identyfikowany wcześniej jako Caloplaca holocarpa (Hoffm.) Arup, Frödén \& Søchting. Ocena występowania w poszczególnych mezoregionach wymaga rewizji zbiorów zielnikowych.

\section{* Athelia arachnoidea s.1.}

Gorce: KuKwa \& CZARnOta (2006); Obniżenie Orawsko-Nowotarskie: KuKWA \& JABŁOŃSKA (2008); Beskid Niski: BIELCZYK i in. (2016).

Uwaga: W wymienionych publikacjach podawano Athelia arachnoidea (Berk.) Jülichs, lecz notowania te oparto o materiał sterylny, stąd możliwym jest występowanie innych gatunków z tej grupy. 
* Athelia epiphylla Pers.

Beskid Sądecki: WoJEwoda (2003); Kotlina Orawsko-Nowotarska: WoJEWodA (2003); Bieszczady Zachodnie: WoJEWODA (2003).

Atla alpina Savić \& Tibell

Syn.: Polyblastia thelodes auct. p.p.

Tatry Wysokie: FlaKus $(2007,2014)$.

*Bachmanniomyces punctum (A. Massal.) Diederich \& Pino-Bodas

Syn.: Phaeopyxis punctum (A. Massal.) Rambold, Triebel \& Coppins

Beskid Żywiecki : Kukwa i in. (2010); Gorce: Kukwa i in. (2010); Beskid Sądecki: KuKwa \& KowALEWSKA (2007); Beskid Niski: KuKWA (2005b), BIELCZYK i in. (2016); Tatry Wysokie: CZARnota (2012); Tatry Zachodnie: CZARNOTA (2012).

Bacidia fuscoviridis (Anzi) Lettau

Beskid Makowski: Czarnota (2016); Beskid Wyspowy: Czarnota (2016); Gorce: Czarnota (2010, 2016); Pieniny: CZARnota (2016).

Bacidia viridescens (A. Massal.) Norman

Pogórze Wiśnickie: Śliwa (2010); Beskid Niski: Czarnota \& CopPINS (2007), BIElCZYK i in. (2016).

Uwaga: Status tego gatunku jest niejasny i wymaga poparcia molekularnego; bardzo prawdopodobne, że okazy z Polski reprezentują Bacidina egenula (Nyl.) Vězda w odmianie z jasnym hypothecium (por. CZARNOTA \& GUZOW-KRZEMIŃSKA 2018).

Bacidina adastra (Sparrius \& Aptroot) M. Hauck \& V. Wirth

Beskid Niski: BIElCZYK i in. (2016).

Bacidina brandii (Coppins \& van den Boom) M. Hauck \& V. Wirth

Beskid Mały: CZARnota (2016); Gorce: CzARnota (2016); Beskid Niski: BielcZYK i in. (2016).

Bacidina caligans (Nyl.) Llop \& Hladún

Syn.: Bacidia caligans (Nyl.) A.L. Sm.

Beskid Niski: CZARnota \& COPPINS (2007).

Bacidina chloroticula (Nyl.) Vězda \& Poelt

Gorce: CZARnota \& Wojnarowicz (2008).

Bacidina delicata (Leight.) V. Wirth \& Vězda

Syn.: Bacidia delicata (Leight.) Coppins

Tatry Zachodnie: FlaKus \& BielczYK (2006); Bieszczady Zachodnie: MiądLIKowsKa (1999).

Bacidina mendax Czarnota \& Guz.-Krzem.

Beskid Mały: CZARnota \& GuZow-KrzemińsKa (2018); Gorce: CZARnota (2010), jako Bacidina neosquamulosa (Aptroot \& Herk) S. Ekman; Kotlina Jasielsko-Krośnieńska: CZARnOTA \& GuZow-KrZEMIŃsKA (2018); Beskid Niski: CZARnota \& GuZow-KrZEMińsKa (2018).

Bacidina pycnidiata (Czarnota \& Coppins) Czarnota \& Guz.-Krzem.

Syn.: Bacidia pycnidiata Czarnota \& Coppins

Gorce: Czarnota \& Coppins (2006); Pogórze Strzyżowskie: Czarnota \& Coppins (2006); Beskid Niski: BIELCZYK i in. (2016).

Bacidina saxenii (Erichsen) M. Hauck \& V. Wirth

Syn.: Bacidia saxenii Erichsen

Beskid Niski: CZARnOTA \& CopPIns (2007), BIELCZYK i in. (2016).

Bacidina sulphurella (Samp.) M. Hauck \& V. Wirth

Pogórze Wiśnickie: Śliwa (2010); Gorce: CZarnota (2010); Beskid Niski: BielcZYK i in. (2016); Pininy:

CZARnota \& GuZow-Krzemińska (2012); Tatry Zachodnie: CZarnota (2012). 
Bellemerea diamarta (Ach.) Hafellner \& Cl. Roux

Tatry Wysokie: FlaKus $(2007,2014)$.

Bellemerea subsorediza (Lynge) R. Sant.

Tatry Wysokie: FlaKus (2007, 2014), ŚLIWA \& FlaKus (2011).

Biatora flavopunctata (Tønsberg) Hinter. \& Printzen

Bieszczady Zachodnie: KoŚcIELNIAK (2008, 2013).

Biatora hemipolia (Nyl.) S. Ekman \& Printzen

Syn.: Bacidia hemipolia f. pallida Czarnota \& Coppins

Góry Sanocko-Turczańskie: CZARnOTA \& COPPINS (2007).

Biatora pontica Printzen \& Tønsberg

Pogórze Przemyskie: Czarnota i in. (2018).

Biatora subduplex (Nyl.) Printzen

Tatry Wysokie: Flakus (2007) jako Biatora vernalis (L.) Fr.

*Biatoropsis usnearum s.l.

Pieniny: KUKWA i in. (2013).

Uwaga: W wymienionej pracy podawany jako Biatoropsis usnearum Räsänen, jednak ostatnie badania MiLlANES i in. (2016) z wykorzystaniem danych molekularnych wskazują na możliwość pomyłki z innymi taksonami w obrębie tego gatunku zbiorczego.

Blastenia scabrosa (Søchting, Lorentsen \& Arup) S.Y. Kondratyuk, I. Kärnefelt, J.A. Elix, A. Thell, J. Kim, A.S. Kondr. \& J.-S. Hur

Syn.: Caloplaca scabrosa Søchting, Lorentsen \& Arup

Tatry Zachodnie: WILK (2015); Tatry Wysokie: WILK (2015).

Brianaria tuberculata (Sommerf.) S. Ekman \& M. Svensson

Syn.: Micarea tuberculata (Sommerf.) R.A. Anderson

Tatry Wysokie: Flakus (2004), Czarnota (2007a).

Bryobilimbia ahlesii (Körb.) Fryday, Printzen \& S. Ekman

Beskid Sądecki: Matura i in. (2017).

Bryostigma muscigenum (Th. Fr.) Frisch \& G. Thor

Syn.: Arthonia muscigena Th. Fr.

Gorce: Czarnota (2010); Pogórze Przemyskie: Kościelniak \& Baran (2018); Tatry Wysokie: Flakus (2007, 2014); Bieszczady Zachodnie: KośCIELNIAK (2013).

Buellia arborea Coppins \& Tønsberg

Tatry Wysokie: KuKwA i in. (2017).

* Burgoa angulosa Diederich, Lawrey \& Etayo

Beskid Niski: BIELCZYK i in. (2016).

Calicium pinastri Tibell

Rów Podtatrzański: ŚlıwA \& KuKwa (2008).

Calogaya arnoldiiconfusa (Gaya \& Nav.-Ros.) Arup, Frödén \& Søchting

Tatry Zachodnie: WILK (2012).

Calogaya pusilla (A. Massal.) Arup, Frödén \& Søchting

Syn.: Caloplaca pusilla (A. Massal.) Zahlbr.

Gorce: WILK (2011, 2012); Pieniny: WILK (2011, 2012).

Caloplaca albolutescens (Nyl.) H. Olivier

Beskid Makowski: WILK (2012); Beskid Wyspowy: WILK (2012); Kotlina Żywiecka: WILK (2012); Gorce:

WILK (2012); Beskid Niski: WILK (2012); Pieniny: WILK (2012). 
Uwaga: Gatunek ujęty tradycyjnie w rodzaju Caloplaca; według K. WILK takson o niepewnej pozycji systematycznej, pomimo ostatniej zmiany nomenklaturowej na Pyrenodesmia albolutescens (Nyl.) S.Y. Kondr., zaproponowanej przez KONDRATYUKA i in. (2020).

Caloplaca albopruinosa (Arnold) H. Olivier

Tatry Zachodnie: WILK $(2011,2012)$.

Uwaga: Gatunek ujęty tradycyjnie w rodzaju Caloplaca, ale według K. WILK takson o niepewnej pozycji systematycznej; nazwa Biatorina albopruinosa Arnold, zaproponowana w MYCoBANK FUNGAL DATABASE jako obowiązująca dla tego taksonu budzi także wątpliwości.

Caloplaca arnoldii subsp. oblitterata (Pers.) Gaya

Pogórze Wiśnickie: Ślıwa \& KRZEWICKA (2012a); Gorce: WILK (2012); Pogórze Ciężkowickie: ŚLIWA \& KrZewicka (2012a); Pogórze Dynowskie: Śliwa \& KrZewicka (2012a).

Caloplaca conciliascens (Nyl.) Zahlbr.

Tatry Wysokie: WILK \& FLAKUS (2006).

Caloplaca isidiigera Vězda

Gorce: WILK (2015).

Caloplaca micromontana Frolov, Wilk \& Vondrák

Pieniny: Wilk $(2011,2012)$ jako Caloplaca atroalba (Tuck.) Zahlbr., Frolov i in. (2016); Tatry Zachodnie: Wilk $(2011,2012)$ jako C. atroalba, Frolov i in. (2016).

Caloplaca microstepposa Frolov, Nadyeina, Khodos. \& Vondrák

Pogórze Przemyskie: Frolov i in. (2016).

Caloplaca monacensis (Leder.) Lettau

Pogórze Przemyskie: Kubiak \& WiLK (2016); Beskid Niski: KubiaK \& WiLK (2016).

Caloplaca percrocata (Arnold) J. Steiner

Tatry Zachodnie: WILK \& FLAKUS (2006), WILK (2012).

Caloplaca pseudofulgensia Gaya \& Nav.-Ros.

Pieniny: WILK $(2011,2012)$; Tatry Zachodnie: WILK $(2011,2012)$.

Caloplaca soralifera Vondrák \& Hrouzek

Pogórze Przemyskie: WILK \& ŚLIWA (2012), WILK (2012); Kotlina Orawsko-Nowotarska: WILK \& ŚLIWA (2012), WILK (2012); Pieniny: WILK \& ŚLIWA (2012).

* Caloplaca vitellinaria Szatala

Pogórze Wiśnickie: (ŚLIWA 2010); Beskid Śląski: WILK \& FlaKUS (2006), WILK (2012); Tatry Zachodnie: WiLK \& FlaKus (2006).

Candelariella efflorescens R.C. Harris \& W.R. Buck

Pogórze Wiśnickie: Śliwa (2010); Beskid Żywiecki: Węgrzyn (2004); Gorce: Czarnota i in. (2005), Czarnota \& Wojnarowicz (2008), Czarnota (2010); Pogórze Przemyskie: Kościelniak \& Baran (2018); Kotlina Jasielsko-Krośnieńska: StolarczyK (2009); Beskid Niski: BielczyK i in. (2016); Pieniny: KisZKA (2004, 2005); Rów Podtatrzański: ŚLIwA \& KuKwA (2012), ŚLIwA (2006); Tatry Zachodnie: ŚLIwA \& KuKWa (2012); Tatry Wysokie: Węgrzyn (2009); Bieszczady Zachodnie: KośCielniaK \& KisZKA (2005), KościelniaK (2013), KośCielniaK \& Betleja (2013), KapeK (2014).

Uwaga: W większości powyższych notowań jako Candelariella reflexa (Nyl.) Lettau (por. KuBiAK \& WeSTBERg 2011).

* Capronia peltigerae (Fuckel) D. Hawksw.

Bieszczady Zachodnie: MiądLIKOWsKa \& ALSTRuP (1995).

* Carbonea supersparsa (Nyl.) Hertel

Beskid Niski: KuKwa (2005b), BIELCZYK i in. (2016). 
Catillaria contristans (Nyl.) Zahlbr.

Tatry Wysokie: WęGRZYN (2008, 2009).

${ }^{*}$ Cecidonia umbonella (Nyl.) Triebel \& Rambold

Tatry Wysokie: Flakus (2007), KuKWA \& FlaKus (2009).

* Cercidospora lecidomae Zhurb. \& Triebel

Tatry Wysokie: KuKwa \& Flakus (2009).

* Cercidospora punctillata (Nyl.) R. Sant.

Tatry Wysokie: KuKWA \& FlaKus (2009).

* Cercidospora stereocaulorum (Arnold) Hafellner

Tatry Wysokie: KuKWA \& FlaKus (2009).

* Cercidospora trypetheliza (Nyl.) Hafellner \& Obermayer

Tatry Wysokie: KuKWA \& FLAKUS (2009).

Cetrelia chicitae (W.L. Culb.) W.L. Culb. \& C.F. Culb.

Beskid Niski: KuKwa i in. (2012); Bieszczady Zachodnie: KoścIELnIAK (2012), KuKwA i in. (2012).

Cetrelia monachorum (Zahlbr.) W.L. Culb. \& C.F. Culb.

Beskid Śląski: Kukwa i in. (2012); Beskid Mały: Kukwa i in. (2012); Beskid Żywiecki: Kukwa i in. (2012); Gorce: KuKwa i in. (2012); Beskid Sądecki: KuKwa i in. (2012); Pogórze Przemyskie: KuKwa i in. (2012), KościelniaK \& Baran (2018); Kotlina Orawsko-Nowotarska: KuKwa i in. (2012); Góry SanockoTurczańskie: Kukwa i in. (2012); Bieszczady Zachodnie: Kukwa i in. (2012).

* Chaenothecopsis savonica (Räsänen) Tibell

Beskid Żywiecki: KukwA i in. (2010); Gorce: KuKwA i in. (2010); Kotlina Orawsko-Nowotarska: KukwA i in. (2010); Tatry Zachodnie: CZARNOTA (2012).

Cladonia asahinae J.W. Thomson

Beskid Sądecki: KowalewsKa \& KuKwa (2007), KowalewsKa i in. (2008).

Cladonia borealis S. Stenroos

Beskid Żywiecki: OsYCZKA (2006, 2012); Beskid Sądecki: OsYCZKA (2006, 2012); Beskid Niski: BIELCZYK i in. (2016); Tatry Wysokie: OsYCZKa (2006, 2012), FlaKUs $(2007,2014)$.

Cladonia conista (Nyl.) Robbins

Beskid Makowski: KowALEwSKA i in. (2008); Beskid Żywiecki: KowALEwsKA i in. (2008); Gorce: KowALEWSKA i in. (2008); Beskid Sądecki: KowalewsKa i in. (2008); Pogórze Ciężkowickie: KowalewsKa i in. (2008); Pieniny: Kowalewska i in. (2008); Bieszczady Zachodnie: KowalewsKa i in. (2008).

Uwaga: We wcześniejszej literaturze podawany z polskich Karpat jako Cladonia humilis (With.) J.R. Laundon (por. BIELCZYK 2003).

Cladonia cryptochlorophaea Asahina

Beskid Makowski: KowalewsKa i in. (2008), Śliwa \& Matura (2018); Beskid Żywiecki: KowalewsKa i in. (2008); Gorce: Czarnota \& Wojnarowicz (2008), Kowalewska i in. (2008); Beskid Sądecki: KowalewsKa i in. (2008); Bieszczady Zachodnie: KowaLEwsKa i in. (2008).

Cladonia metacorallifera Asahina

Tatry Wysokie: OsYCZKA i in. (2006), OsYCZKA (2011); Bieszczady Zachodnie: OsYCZKA \& KośCIELNIAK (2009), OSYCZKA (2011).

Cladonia strepsilis (Ach.) Grognot

Beskid Mały: ŚLIWA \& MATURA (2018).

\section{Cladonia trassii Ahti}

Tatry Wysokie: Flakus (2004, 2006a, 2007, 2014), WęgrZyn (2009), Śliwa \& Matura (2018). Uwaga: We wcześniejszej literaturze podany z polskich Karpat pod nazwą Cladonia stricta (Nyl.) Nyl. (por. BIELCZYK 2003). 
* Clypeococcum hypocenomycis D. Hawksw.

Beskid Żywiecki: KuKwA i in. (2010); Kotlina Orawsko-Nowotarska: KuKWA \& JABŁoŃSKA (2008).

Dermatocarpon rivulorum (Arnold) Dalla Torre \& Sarnth.

Tatry Wysokie: FlaKus (2007, 2014), MATURA (2020).

Dictyocatenulata alba Finley \& E. F. Morris

Gorce: DieDERICH i in. (2008); Beskid Niski: BIELCZYK i in. (2016).

* Didymocyrtis bryonthae (Arnold) Hafellner

Syn.: Polycoccum bryonthae (Arnold) Vězda

Tatry Wysokie: KuKwa \& Flakus (2009).

Diplotomma scheideggerianum (Bricaud \& Cl. Roux) Nimis

Tatry Zachodnie: WILK (2006).

*Endococcus brachysporus (Zopf) M. Brand \& Diederich

Beskid Żywiecki: KuKWA \& FlaKUS (2009).

* Endococcus fusiger Th. Fr. \& Almq.

Tatry Wysokie: KuKWA \& FlaKus (2009).

"Endococcus macrosporus (Hepp ex Arnold) Nyl.

Tatry Wysokie: KuKWA \& FlaKus (2009).

* Endococcus rugulosus (Borrer ex Leight.) Nyl.

Tatry Wysokie: WęGrzYn (2008), KuKWA \& FlaKus (2009).

* Epibryon conductrix (Norman ex Th. Fr.) Nik. Hoffm. \& Hafellner

Tatry Wysokie: KuKwa \& FlaKus (2009).

*Epibryon solorinae (Vain.) Nik. Hoffm. \& Hafellner

Tatry Wysokie: KuKwa \& Flakus (2009).

*Epicladonia sandstedei (Zopf) D. Hawksw.

Gorce: CZARnota \& Wojnarowicz (2008); Bieszczady Zachodnie: KuKwa \& CZarnota (2006).

* Epicladonia stenospora (Harm.) D. Hawksw.

Tatry Zachodnie: KuKwA \& KowALEWSKA (2007).

Epigloea bactrospora Zukal

Gorce: CZARNOTA \& TANONA (2020).

* Epigloea medioincrassata (Grummann) Döbbeler

Tatry Wysokie: CYKOWSKA \& FLAKUS (2005).

* Epigloea pleiospora Döbbeler

Bieszczady Zachodnie: CEYNOWA-GiEŁdON (2005).

* Epigloea soleiformis Döbbeler

Beskid Żywiecki: Czarnota \& HerniK (2013b); Beskid Sądecki: CZarnota \& HerniK (2013b).

* Epigloea urosperma Döbbeler

Beskid Żywiecki: CZARnota \& HerniK (2013b); Beskid Niski: BIElCZYK i in. (2016).

* Erythricium aurantiacum (Lasch) D. Hawksw. \& A. Henrici

Syn.: Marchandiomyces aurantiacus (Lasch) Diederich \& Etayo

Kotlina Orawsko-Nowotarska: KuKWA \& JABŁOŃSKA (2008).

* Everniicola flexispora D. Hawksw.

Tatry Wysokie: KuKWA \& FlaKus (2009). 
Farnoldia muscigena (Vězda) Clauzade \& Cl. Roux

Syn.: Lecidea jurana var. muscigena Vězda

Tatry: AlstRup \& Olech (1992b).

Fellhanera gyrophorica Sérus., Coppins, Diederich \& Scheid.

Gorce: CZARNOTA \& TANONA (2020).

Fellhaneropsis vezdae (Coppins \& P. James) Sérus. \& Coppins

Tatry Wysokie: FlaKus (2006a).

*Feltgeniomyces luxemburgensis Diederich

Gorce: KunWA \& CZARNOTA (2006).

Flavoplaca dichroa (Arup) Arup, Frödén \& Søchting

Syn.: Caloplaca dichroa Arup

Beskid Mały: WiLK (2011, 2012); Pieniny: WILK (2011, 2012); Tatry Zachodnie: WILK $(2011,2012)$.

Flavoplaca flavocitrina (Nyl.) Arup, Frödén \& Søchting

Syn.: Caloplaca flavocitrina (Nyl.) H. Olivier

Kotlina Żywiecka: Wilk (2012); Gorce: Czarnota \& Wojnarowicz (2008), Wilk (2012); Pogórze Rożnowskie: WILK (2012); Beskid Niski: BIELCZYK i in. (2016); Bieszczady Zachodnie: KośCIELNIAK (2013).

Flavoplaca oasis (A. Massal.) Arup, Frödén \& Søchting

Syn.: Caloplaca oasis (A. Massal.) Szatala

Gorce: CZARnota (2010), Wilk (2011, 2012); Beskid Niski: BielCZYK i in. (2016); Pieniny: WiLK (2012).

Fuscidea arboricola Coppins \& Tønsberg

Beskid Niski: BIELCZYK i in. (2016).

Fuscidea cyathoides (Ach.) V. Wirth \& Vězda var. cyathoides

Bieszczady Zachodnie: KościelnIAK (2013).

Fuscidea cyathoides var. corticola (Fr.) H. Magn.

Bieszczady Zachodnie: KościELNIAK (2013).

Gallowayella fulva (Hoffm.) S.Y. Kondr., Fedorenko, S. Stenroos, Kärnefelt, Elix, Hur \& A. Thell

Syn.: Xanthoria candelaria var. fulva Arnold, Xanthoria fulva (Hoffm.) Poelt \& Petutschnig

Pieniny: ToBoLEwSKI (1958); Bieszczady Zachodnie: KAPEK (2014).

* Graphium aphthosae AlSTRUP \& D. Hawksw.

Tatry Wysokie: KuKWA \& JABŁOŃSKA (2008).

Gyalecta peziza (Mont.) Anzi

Tatry Wysokie: FlaKus (2005, 2007, 2014).

Gyalecta russula (Körb. ex Nyl.) Baloch, Lumbsch \& Wein

Gorce: CZARNOTA \& TANONA (2020).

Gyalecta sudetica Vězda

Tatry Wysokie: FlaKus \& BIELCZYK (2006).

Gyalidea subscutellaris (Vězda) Vězda

Tatry Wysokie: FlaKus $(2007,2014)$.

Haematomma ochroleucum (Neck.) J.R. Laundon var. ochroleucum

Beskid Sądecki: ZDUŃCZYK \& KUKWA (2012, 2014).

Haematomma ochroleucum var. porphyrium (Pers.) J.R. Laundon

Gorce: CZARnota i in. (2005), ZduńCZYK \& KuKWA (2012).

Halecania viridescens Coppins \& P. James

Pieniny: KUKWA \& JABŁOŃSKA (2009); Beskid Niski: BIELCZYK i in. (2016). 
Heppia lutosa (Ach.) Nyl.

Gorce: Glanc \& ToBolewsKi (1965), CZARnota i in. (2005).

Helocarpon crassipes Th. Fr.

Tatry Wysokie: Czarnota (2007a), Flakus (2007, 2014); Beskid Żywiecki: CZarnota (2007a), CzarNOTA \& WĘGRZYN (2012); Bieszczady Zachodnie: KośCIELNIAK (2013).

${ }^{*}$ Heterocephalacria bachmannii (Diederich \& M.S. Christ.) Millanes \& Wedin

Syn.: Syzygospora bachmannii Diederich \& M.S. Christ.

Tatry Zachodnie: KuKwa \& KowalewsKa (2007).

Hypotrachyna afrorevoluta (Krog \& Swinscow) Krog \& Swinscow

Pogórze Przemyskie: KościelniaK \& Baran (2018); Beskid Niski: Flakus \& KuKwa (2009); Bieszczady Zachodnie: KościelNIAK (2013).

${ }^{*}$ Intralichen lichenicola (M.S. Christ. \& D. Hawksw.) D. Hawksw. \& M.S. Cole Beskid Niski: BIELCZYK i in. (2016).

Jamesiella anastomosans (P. James \& Vězda) Lücking, Sérus. \& Vězda Góry Sanocko-Turczańskie: Czarnota \& Kukwa [2006 (2007)].

Japewia subaurifera Muhr. \& Tønsberg

Beskid Żywiecki: Czarnota (2009); Gorce: Czarnota (2009); Tatry Wysokie: Czarnota \& Kukwa (2004).

Japewia tornoensis (Nyl.) Tønsberg

Gorce: CZARNOTA (2009).

* Karsteniomyces peltigerae (P. Karst.) D. Hawksw.

Beskid Żywiecki: MiąDLIKowsKa \& AlstruP (1995).

Lecania cuprea (A. Massal.) van den Boom \& Coppins

Pieniny: CzArnota (2015); Beskid Sądecki: CZarnota (2015).

Lecania rabenhorstii (Hepp.) Arnold

Syn.: Lecania erysibe var. rabenhorstii (Hepp) Mudd

Beskid Sądecki: Olech (1973).

Lecania sambucina (Körb.) Zahlbr.

Gorce: CZARNOTA \& WOJNAROWICZ (2008).

Lecanora aitema (Ach.) Hepp

Beskid Wyspowy: Czarnota i in. (2010); Beskid Żywiecki: CZARnota i in. (2010); Gorce: CzArnota i in. (2010); Tatry Zachodnie: CZARnOTA (2012).

Lecanora allophana f. sorediata Vain.

Gorce: CZARNOTA \& WoJNAROWICZ (2008).

Lecanora bicincta Ramond

Tatry Wysokie: FlaKus (2007, 2014).

Lecanora bicinctoidea Blaha \& Grube

Tatry Wysokie: FlaKus (2007, 2014).

Lecanora cavicola Creveld

Tatry Wysokie: FlaKus $(2007,2014)$.

Lecanora compallens Herk \& Aptroot

Beskid Mały: KuKwa (2006); Gorce: CZarnota (2010); Beskid Sądecki: ZduńcZYK \& Kukwa (2014); Rów Podtatrzański: Śliwa \& Kukwa (2012), ZduńcZYK \& Kukwa (2014); Tatry Zachodnie: Czarnota (2012); Tatry Wysokie: CZARnOTA (2012). 
Lecanora flavoleprosa Tønsberg

Tatry Zachodnie: CZARnota i in. (2009); Tatry Wysokie: CZARnota i in. (2009), Flakus (2014), ZduńCZYK \& KUKWA (2014).

Lecanora leptacinella $\mathrm{Nyl}$.

Tatry Wysokie: FlaKus (2014).

Lecanora microloba Śliwa \& Flakus

Tatry Wysokie: Śliwa \& Flakus (2011), Flakus (2014), Matura (2016, 2020).

Lecanora orosthea (Ach.) Ach.

Pogórze Wiśnickie: Ślıwa \& Krzewicka (2012a); Pogórze Ciężkowickie: Ślıwa \& KRZEwICKA (2012a); Pogórze Dynowskie: ŚliwA \& KRZEWICKA (2012a), ZDuŃCZYK \& KuKWA (2014).

Lecanora printzenii Pérez-Ortega, Vivas \& Hafellner

Tatry Wysokie: FlaKUS \& ŚliwA (2012).

Lecanora stenotropa $\mathrm{Nyl}$.

Tatry Wysokie: FlaKus $(2007,2014)$.

Lecanora substerilis Malíček \& Vondrák

Gorce: CZARNOTA i in. (2018).

Lecanora swartzii (Ach.) Ach. subsp. swartzii

Tatry Wysokie: FlaKus $(2007,2014)$.

Lecanora swartzii subsp. caulescens (J. Steiner) Leuckert \& Poelt

Tatry Wysokie: FlaKus (2014).

Lecanora swartzii subsp. nylanderi (Räsänen) Leuckert \& Poelt

Tatry Wysokie: FlaKus $(2007,2014)$.

Lecanora thysanophora R.C. Harris

Beskid Żywiecki: Kunwa (2005a), ZduńCZYK \& Kunwa (2014); Gorce: CZARnota i in. (2005), KukwA (2005a), ZDUŃCZYK \& KUKWA (2014); Beskid Niski: ZDUŃCZYK \& KUKWA (2014); Bieszczady Zachodnie: KoŚCIELNIAK (2013).

Lecidea atrobrunnea (DC.) Schaer. subsp. atrobrunnea

Tatry Wysokie: FlaKus (2014).

Lecidea atrobrunnea subsp. saxosa Hertel \& Leuckert

Tatry Wysokie: FlaKus (2014).

Lecidea atrobrunnea subsp. stictica Hertel \& Leuckert

Tatry Wysokie: FlaKus (2014).

Lecidea auriculata Th. Fr. subsp. auriculata

Tatry Wysokie: FlaKus (2014).

Lecidea auriculata subsp. brachyspora Th. Fr.

Tatry Wysokie: FlaKus (2014).

Lecidea leprarioides Tønsberg

Beskid Żywiecki: CZARnota \& Węgrzyn (2012); Gorce: CzArnota (2010); Tatry Zachodnie: CZARnota (2012); Tatry Wysokie: CZARnota (2012).

Lecidea variegatula $\mathrm{Nyl}$.

Pogórze Ciężkowicke: Czarnota (2007b); Gorce: CZARnota i in. (2005), CZARnota (2007b).

\# Leocarpus fragilis (Dicks.) Rostaf.

Syn.: Leocarpus vernicosus (Pers.) Link

Pogórze Wielickie: ROUPPERT (1912); Tatry: ROUPPERT (1912). 
Lepra ocellata (Körb.) Hafellner

Syn.: Pertusaria ocellata Körb.

Beskid Niski: BIELCZYK i in. (2016).

Lepra ophthalmiza (Nyl.) Hafellner

Syn.: Pertusaria ophthalmiza (Nyl.) Nyl.

Rów Podtatrzański: OsET \& KuKwa (2010); Tatry Wysokie: OsET \& Kukwa (2010).

Lepraria diffusa var. chrysodetoides (J.R. Laundon) Kukwa

Gorce: CZARNOTA \& KuKWA (2004).

Lepraria ecorticata (J.R. Laundon) Kukwa

Beskid Wyspowy: KuKwa (2006); Gorce: KuKwA (2006).

Lepraria granulata Slavíková-Bayerová

Tatry Wysokie: KuKWA \& JABŁOŃSKA (2009).

Lepraria jackii var. toensbergiana (Bayerová \& Kukwa) Kukwa

Syn: Lepraria toensbergiana Bayerová \& Kukwa

Tatry Wysokie: BAYerová i in. (2005); Rów Podtatrzański: Ślıwa \& KuKWA (2012).

Lepraria nivalis J.R. Laundon

Tatry Zachodnie: CZARnota \& KuKWa (2004), Flakus (2006a); Tatry Wysokie: KuKWA (2004), WĘGRZYN (2009).

Leproplaca obliterans (Nyl.) Arup, Frödén \& Søchting

Syn.: Caloplaca obliterans (Nyl.) Blomb. \& Forssell

Tatry Wysokie: WiLK \& Flakus (2006).

\# Licea parasitica (Zukal) G.W. Martin

Beskid Niski: BIELCZYK i in. (2016); Kotlina Orawsko-Nowotarska: KuKWA \& JABŁOŃSKA (2008); Bieszczady Zachodnie: KuKwa (2005b).

* Lichenoconium pyxidatae (Oudem.) Petr. \& Syd.

Beskid Żywiecki: KuKwa \& KowalewsKa (2007); Gorce: KuKwa i in. (2010); Tatry Wysokie: KuKwa \& FlaKUS (2009).

* Lichenodiplis lecanorae (Vouaux) Dyko \& D. Hawksw.

Gorce: Kukwa \& Czarnota (2006), CZarnota \& Wojnarowicz (2008); Beskid Niski: Bielczyk i in. (2016); Tatry Zachodnie: ŚLIWA (2006).

* Lichenopeltella peltigericola (D. Hawksw.) R. Sant.

Gorce: MiądLiKowsKa (1999); Tatry Zachodnie: MiąDLiKowSKa (1999).

* Lichenopeltella santessonii (P.M. Kirk \& Spooner) R. Sant.

Bieszczady Zachodnie: MiądLikowsKa \& Alstrup (1995), MiądlikowsKa (1999).

* Lichenosticta alcicornaria (Linds.) D. Hawksw.

Beskid Sądecki: Kukwa \& Czarnota (2006), Kukwa \& Kowalewska (2007); Tatry Wysokie: Kukwa \& FlaKus (2009).

* Lichenostigma alpinum (R. Sant., Alstrup \& D. Hawksw.) Ertz \& Diederich

Syn: Phaeosporobolus alpinus R. Sant., Alstrup \& D. Hawksw. (stadium anamorficzne)

Tatry Wysokie: KuKwa \& Flakus (2009).

* Lichenostigma elongata Nav.-Ros. \& Hafellner

Gorce: Kukwa \& CZARnOTA (2006); Kotlina Orawsko-Nowotarska: Kukwa \& JABŁOŃSKA (2008).

* Lichenostigma maureri Hafellner

Syn.: Phaeosporobolus usneae D. Hawksw. \& Hafellner (stadium anamorficzne) 
Beskid Śląski: KuKwa i in. (2013); Beskid Żywiecki: KuKwA i in. (2013); Gorce: KuKwA i in. (2013); Beskid Sądecki: Kukwa i in. (2013); Pieniny: Kukwa i in. (2013); Pogórze Spisko Gubałowskie: Kukwa $\mathrm{i}$ in. (2013).

${ }^{*}$ Llimoniella adnata Hafellner \& Nav.-Ros.

Tatry Wysokie: KuKWA \& FlaKUS (2009).

* Llimoniella catapyrenii Zhurb., Kukwa \& Flakus

Tatry Wysokie: ZHURBENKo (2013).

Melanelia agnata (Nyl.) A. Thell

Tatry Zachodnie: SzCZEPAŃSKA \& KosSOwSKA (2017); Tatry Wysokie: SZCZEPAŃSKA \& KosSOwSKA (2017).

* Merismatium heterophractum (Nyl.) Vouaux

Tatry Zachodnie: KuKwA \& CZARNOTA (2006).

Micarea anterior (Nyl.) Hedl.

Beskid Wyspowy: Czarnota (2007a); Beskid Żywiecki: Czarnota (2007a); Beskid Sądecki: Czarnota (2007a); Gorce: CZarnota (2004, 2007a, 2012), Czarnota i in. (2005); Kotlina Orawsko-Nowotarska: CZArnota (2007a); Tatry Zachodnie: Czarnota (2007a); Tatry Wysokie: Czarnota (2012).

Micarea byssacea (Th. Fr.) Czarnota, Guzow-Krzemińska \& Coppins

Beskid Żywiecki: CZarnota \& Węgrzyn (2012); Gorce: Czarnota \& GuZow-KrzemińsKa (2010); Tatry Zachodnie: CZARnota (2012); Tatry Wysokie: CzARnota (2012); Bieszczady Zachodnie: KościelNIAK (2013).

Micarea cinerea f. tenuispora (D. Hawksw. \& Poelt) Fryday

Tatry Wysokie: CZARnota (2007a), Flakus $(2007,2014)$.

Micarea contexta Hedl.

Tatry Zachodnie: CZARNOTA (2011).

Micarea czarnotae Launis, van den Boom, Sérusiaux \& Myllys

Beskid Niski: LAUNIS i in. (2019).

Micarea deminuta Coppins

Tatry Wysokie: CzARnota (2004, 2007a).

Micarea globulosella (Nyl.) Coppins

Gorce: CZARNOTA (2007a).

Micarea incrassata Hedl.

Tatry Wysokie: Tobolewski (1959) jako Lecidea assimilata Nyl., Czarnota (2004, 2007a), Flakus (2007, 2014).

Micarea leprosula (Th. Fr.) Coppins \& A. Fletcher

Beskid Makowski: CZarnota (2007a); Beskid Żywiecki: CZarnota (2007a), CZarnota \& Węgrzyn (2012); Tatry Zachodnie: CZARnota (2004, 2007a); Tatry Wysokie: CZARnota (2004, 2007a), WęGrzyN (2009), Flakus (2014); Bieszczady Zachodnie: Czarnota (2004, 2007a), KościelniaK (2013).

Micarea lynceola (Th. Fr.) Palice

Beskid Żywiecki: CZARnOta (2011).

Micarea marginata Coppins \& Muhr

Beskid Żywiecki: CZARnota (2007a); Tatry Wysokie: CZARnota (2004, 2007a), WĘGRZYn (2009).

Micarea micrococca (Körb.) Coppins

Pogórze Wiśnickie: Czarnota (2007a), Ślıwa (2010); Beskid Śląski: CZarnota (2007a); Beskid Wyspowy: Czarnota (2007a); Beskid Żywiecki: CZARnota (2007a); Gorce: CZarnota (2007a), CzarNOTA \& Wojnarowicz (2008); Beskid Sądecki: Czarnota (2007a); Pogórze Rożnowskie: Czarnota (2007a); Pogórze Strzyżowskie: Czarnota (2007a); Pogórze Dynowskie: Czarnota (2007a); Pogórze 
Przemyskie: CZarnota (2007a), Kościelniak \& Baran (2018); Beskid Niski: CZarnota (2007a), BielCZYK i in. (2016); Kotlina Orawsko-Nowotarska: CZARNOTA (2007a); Tatry Zachodnie: CZARNOTA (2007a); Góry Sanocko-Turczańskie: Czarnota (2007a); Bieszczady Zachodnie: CZARnota (2007a), KośCIELNIAK (2013).

Uwaga: We wcześniejszej literaturze podawany z polskich Karpat w ramach zbiorczego taksonu Micarea prasina s.1. (por. CZARNOTA 2007a).

Micarea nowakii Czarnota \& Coppins

Beskid Mały: CZarnota (2007a); Gorce: CZARnota (2007a); Beskid Żywiecki: CZARnota \& Węgrzyn (2012); Tatry Wysokie: CZARnota (2012).

Micarea polycarpella (Erichsen) Coppins

Beskid Wyspowy: CzARnota (2004, 2007a).

Micarea pycnidiophora Coppins \& P. James

Gorce: CZARNOTA (2015).

Micarea soralifera Guzow-Krzemińska, Czarnota, Łubek \& Kukwa

Beskid Żywiecki: GuZow-KrZemińska i in. (2016); Gorce: GuZow-KrZemińska i in. (2016); Pogórze Przemyskie: GuZow-KrZEMIŃsKA i in. (2016); Tatry Wysokie: GuZow-KrZEMIŃsKA i in. (2016).

Micarea submilliaria (Nyl.) Coppins

Tatry Wysokie: Czarnota (2004, 2007a), Flakus (2007, 2014).

Micarea tomentosa Czarnota \& Coppins

Pieniny: CZARnota (2007a); Tatry Wysokie: CzARnota (2012).

Micarea viridileprosa Coppins \& van den Boom

Pogórze Wielickie: Czarnota (2004); Pogórze Wiśnickie: Czarnota (2007a), Śliwa (2010); Beskid Mały: Czarnota (2007a); Beskid Żywiecki: Czarnota (2007a); Gorce: CZARnota (2004, 2007a), Czarnota \& Wojnarowicz (2008); Pogórze Dynowskie: Czarnota (2007a); Beskid Niski: BielczyK i in. (2016); Kotlina Orawsko-Nowotarska: CZARnOTA (2007a).

* Minutoexcipula tuerkii Hafellner

Tatry Wysokie: KuKwa \& Flakus (2009).

Miriquidica intrudens (H. Magn.) Hertel \& Rambold

Tatry Wysokie: KuKwa \& FlaKus (2009), Flakus (2014).

Miriquidica pycnocarpa (Körb.) M.P. Andreev

Bieszczady Zachodnie: KośCIELNIAK (2013).

Mniaecia jungermaniae (Fr.) Boud.

Gorce: CZARNOTA \& HERNIK (2013a).

* Monodictys epilepraria Kukwa \& Diederich

Beskid Śląski: KuKWA \& JABŁOŃSKA (2008); Beskid Żywiecki: KuKwa i in. (2010); Gorce: KuKwA \& DiEDERICH (2005), KuKWA \& JABŁoŃSKA (2008), KuKwa i in. (2010); Beskid Sądecki: KuKWA \& Diederich (2005); Beskid Niski: BIElCZYK i in. (2016); Tatry Zachodnie: CZARnota (2012); Tatry Wysokie: CzARNOTA (2012); Bieszczady Zachodnie: KuKwa \& Diederich (2005), KuKwa \& Flakus (2009).

* Muellerella erratica (A. Massal.) Hafellner \& Volk. John

Tatry Wysokie: KuKWA \& FlaKus (2009).

*Muellerella lichenicola (Sommerf.) D. Hawksw.

Gorce: Kukwa \& CZARnota (2006), CZARnota \& Wojnarowicz (2008); Tatry Wysokie: Kukwa \& FlaKus (2009).

* Muellerella ventosicola (Mudd) D. Hawksw.

Tatry Wysokie: Węgrzyn (2008), KuKWA \& Flakus (2009). 
Multiclavula mucida (Pers.) R.H. Petersen

Beskid Niski: BIELCZYK i in. (2016); Bieszczady Zachodnie: KoŚCIELNIAK (2013), KośCIELNIAK i in. (2016).

Mycomicrothelia confusa D. Hawksw.

Beskid Niski: BIELCZYK i in. (2016).

Myriolecis persimilis (Th. Fr.) Śliwa, Zhao Xin \& Lumbsch

Syn.: Lecanora persimilis (Th. Fr.) Arnold

Beskid Niski: BIELCZYK i in. (2016).

Myriolecis semipallida (H. Magn.) Śliwa, Zhao Xin \& Lumbsch

Syn.: Lecanora flotoviana auct. non Spreng.

Pogórze Wielickie: ŚLIWA (2009); Pogórze Wiśnickie: ŚLIWA (2009); Beskid Mały: ŚLIWA (2009); Beskid Makowski: Ślıwa (2009); Kotlina Żywiecka: Ślıwa (2009); Gorce: CZARnota \& Wojnarowicz (2008), ŚlıwA (2009); Beskid Sądecki: Ślıwa (2009); Pogórze Ciężkowickie: Ślıwa (2009); Pogórze Przemyskie: KośCielniaK \& BARAN (2018); Beskid Niski: BIElCZYK i in. (2016); Góry Sanocko-Turczańskie: Śliwa (2009); Pieniny: Śliwa (2009); Rów Podtatrzański: ŚLrwa (2009); Tatry Zachodnie: Ślıwa (2009); Tatry Wysokie: FlaKus (2014); Bieszczady Zachodnie: KoŚcIELNIAK (2013).

Myriospora cf. myochroa (M. Westb.) K. Knudsen \& L. Arcadia

Tatry Wysokie: FlaKus (2014).

* Niesslia peltigericola (D. Hawksw.) Etayo

Tatry Wysokie: KuKWA \& Flakus (2009).

Ochrolechia bahusiensis H. Magn.

Beskid Śląski: KuKwA (2011); Beskid Żywiecki: KuKwA (2011); Bieszczady Zachodnie: KuKwA (2011).

Ochrolechia szatalaensis Verseghy

Beskid Żywiecki: KuKwa (2009, 2011); Rów Podtatrzański: Kukwa (2009, 2011); Tatry Zachodnie: KuKWA $(2009,2011)$.

Ochrolechia trochophora (Vain.) Oshio

Bieszczady Zachodnie: KuKwa (2009, 2011).

* Opegrapha geographicola (Arnold) Hafellner

Tatry Wysokie: KUKWA \& FLAKUS (2009).

Opegrapha saxicola Ach.

Beskid Mały: WieczoreK (2018); Pieniny: WieCZoreK (2018); Tatry Zachodnie: WieCZoreK (2018).

Uwaga: We wcześniejszej literaturze podany jako synonim Opegrapha rupestris Pers. (por. BIELCZYK 2003).

Palicella filamentosa (Stirt.) Rodr. Flakus\& Printzen

Syn.: Lecanora filamentosa (Stirt.) Elix \& Palice, Lecanora ramulicola (H. Magn.) Printzen \& P.F. May

Beskid Mały: Czarnota i in. (2010); Beskid Żywiecki: Czarnota i in. (2010); Pogórze Rożnowskie: Czarnota i in. (2010); Gorce: Czarnota (2010); Pogórze Przemyskie: Kościelniak \& Baran (2018); Rów Podtatrzański: Czarnota i in. (2010); Tatry Wysokie: Czarnota i in. (2010).

Uwaga: We wcześniejszych opracowaniach z polskich Karpat wymieniany także pod nazwą Lecidea ramulicola (H. Magn.) Hillm. lub błędnie jako Lecanora symmicta (Ach.) Ach. i L. cadubriae (A. Massal.) Hedl. (por. CZARNOTA i in. 2010).

Parabagliettoa disjuncta (Arnold) Krzewicka Tatry Zachodnie: KRZEWICKA (2012).

Parmelia barrenoae Divakar, M.C. Molina \& A. Crespo

Kotlina Żywiecka: OssowsKa \& KuKwa (2016); Pogórze Ciężkowickie: OssowsKa \& KuKWA (2016); Pogórze Dynowskie: Ossowska \& Kukwa (2016); Pogórze Przemyskie: OssowsKa \& Kukwa (2016); 
Pogórze Spisko-Gubałowskie: OssowsKa \& KuKwA (2016); Góry Sanocko-Turczańskie: OssowsKA \& KuKwa (2016).

Parmelia ernstiae Feuerer \& A. Thell

Bieszczady Zachodnie: KośCIELNIAK (2013).

Parmelia pinnatifida Kurok.

Tatry Zachodnie: OssowsKa \& KuKwa (2016); Tatry Wysokie: OssowsKa \& KuKwa (2016).

Parmelia serrana A. Crespo, M.C. Molina \& D. Hawksw.

Beskid Śląski: Ossowska i in. (2014); Gorce: OssowsKa i in. (2014); Pogórze Przemyskie: OssowsKa i in. (2014); Pieniny: Ossowska i in. (2014); Góry Sanocko-Turczańskie: OssowsKa i in. (2014); Bieszczady Zachodnie: OssowsKa i in. (2014).

Parmotrema stuppeum (Taylor) Hale

Bieszczady Zachodnie: JABŁoŃsKa i in. (2009), KoŚCIELNIAK (2013).

Peltigera monticola Vitik.

Gorce: UGDA-L-4546, leg. K. Glanc, det. O. Vitikainen; Tatry Zachodnie: MiąDLIKowsKa (1999); Tatry Wysokie: MiąDLIKOWSKA (1999).

Peltigera neopolydactyla (Gyeln.) Gyeln.

Beskidy Zachodnie: MiąDLIKowsKa (1999); Tatry Zachodnie: MiąDLIKowsKA (1999).

Pertusaria pupillaris (Nyl.) Th. Fr.

Beskid Żywiecki: WęGRZYN (2004); Beskid Niski: BIELCZYK i in. (2016); Tatry Zachodnie: ŚLIwA \& KUKWA (2012).

* Phacographa glaucomaria (Nyl.) Hafellner

Syn.: Opegrapha glaucomaria (Nyl.) Källsten

Tatry Wysokie: KuKwa \& Flakus (2009).

Phaeophyscia cernohorskyi (Nádv.) Essl.

Syn.: Physcia cernohorskyi Nádv.

Bieszczady Zachodnie: Glanc \& Tobolewski (1960), KościelniaK \& KiszKa (2005), KościelniaK (2012).

* Phaeospora peltigericola D. Hawksw.

Tatry Wysokie: KuKWA \& JABŁOŃSKA (2008).

* Phaeospora rimosicola (Leight. ex Mudd) Hepp ex Stein

Tatry Wysokie: KuKWA \& FLAKUS (2009).

* Phaeosporobolus usneae D. Hawksw. \& Hafellner

Beskid Śląski: Kukwa i in. (2013); Beskid Żywiecki: KuKwA i in. (2013); Gorce: KuKwA i in. (2013); Beskid Sądecki: Kukwa i in. (2013); Pieniny: Kukwa i in. (2013); Pogórze Spisko Gubałowskie: Kukwa i in. (2013).

*Phoma denigricans Hafellner

Tatry Wysokie: KuKWA \& Flakus (2009).

Uwaga: Prawdodobnym jest, że $P$. denigricans jest tylko stadium anamorficznym Didymocyrtis bryonthae (Arnold) Hafellner (por. ERTz i in. 2015), gatunku stwierdzonego także w Tatrach przez KuKwE i FlAKUSA (2009).

Placopyrenium canellum (Nyl.) Gueidan \& Cl. Roux Gorce: KrZewicka (2009b, 2012), Pieniny: KrzeWicka (2009b, 2012), Góry Sanocko-Turczańskie: KRZEWICKA (2012).

Placopyrenium trachyticum (Hazsl.) Breuss

Pieniny: Breuss (2009), KRZEWICKA (2012). 
Placynthium dolichoterum (Nyl.) Trevis.

Tatry Wysokie: FlaKus (2006b, 2007, 2014).

Polyblastia fuscoargillacea Anzi

Tatry Wysokie: Flakus \& BielczyK (2006), FlaKus (2007, 2014).

Polycauliona phlogina (Ach.) Arup, Frödén \& Søchting

Syn.: Caloplaca phlogina (Ach.) Flagey

Beskid Niski: BIELCZYK i in. (2016).

* Polycoccum minutulum Kocourk. \& F. Berger

Gorce: KuKwA \& CZARNOTA (2006).

* Polycoccum sporastatiae (Anzi) Arnold

Tatry Wysokie: KuKwA \& FlaKus (2009).

* Polysporina subfuscescens (Nyl.) K. Knudsen \& Kocourk.

Tatry: KNUdSEN \& KoCOURKovÁ (2008).

Porpidia contraponenda (Arnold) Knoph \& Hertel

Beskid Śląski: JABŁOŃSKA (2012); Beskid Mały: JABŁOŃSKA (2012); Beskid Żywiecki: JABŁOŃSKA (2012);

Gorce: JABŁoŃSKA (2012); Rów Podtatrzański: JABŁoŃSKA (2012); Tatry Zachodnie: JABŁoŃsKA (2012);

Tatry Wysokie: JABŁOŃSKA (2012); Bieszczady Zachodnie: JABŁOŃSKA (2012).

Porpidia grisea Gowan

Beskid Wyspowy: JABŁOŃSKA (2010, 2012); Gorce: JABŁOŃSKA (2010, 2012); Beskid Sądecki: JABŁOŃSKA (2010, 2012).

Porpidia speirea var. alpina (Arnold) Clauzade \& Cl. Roux

Beskid Żywiecki: JABŁońsKA (2012); Gorce: JABŁońsKA (2012); Beskied Sądecki: JABŁoŃSKA (2012); Tatry Wysokie: FlaKus (2007, 2014), JABŁońSKA (2012).

Porpidia speirea var. prochsthallina Clauzade \& $\mathrm{Cl}$. Roux

Tatry Wysokie: FlaKus (2007, 2014), JABŁońSKA (2012).

Porpidia thomsonii Gowan

Beskid Sądecki: JabŁoŃSKa (2012), Matura (2020); Tatry Wysokie: JabŁońsKa (2012), FlaKus (2014), MATURA (2020).

* Pronectria erythrinella (Nyl.) Lowen

Pieniny: MiądLIKOWSKA (1999).

Protoparmelia hypotremella Herk, Spier \& V. Wirth

Pogórze Wiśnickie: Śliwa (2010); Gorce: CZARnota \& WojnARowicz (2008); Rów Podtatrzański: Śliwa 2006; Bieszczady Zachodnie: KościelniaK \& KISZKA (2006);

Puttea margaritella (Hulting) S. Stenroos \& Huhtinen

Gorce: CZARnota \& HerniK (2013a); Tatry Wysokie: CZARnota \& Hernik (2013a).

Pycnora xanthococca (Sommerf.) Hafellner

Syn.: Lecidea xanthococca Sommerf.

Tatry Zachodnie: ToвoLEWSKI (1969); Tatry Wysokie: NowAK (1974).

${ }^{*}$ Pyrenidium actinellum Nyl.

Gorce: KuKWA \& CZARNOTA (2006).

Pyrenula chlorospila (Nyl.) Arnold

Bieszczady Zachodnie: ALSTRUP (2004).

Ramonia chrysophaea (Pers.) Vězda

Pogórze Przemyskie: Czarnota i in. (2018). 
* Rhagadostoma boleae Nav.-Ros. \& Hladún

Tatry Wysokie: KuKWA \& FlaKus (2009).

* Rhagadostoma rugosum Nav.-Ros. \& Hladún

Tatry Wysokie: KuKWA \& Flakus (2009).

Rhizocarpon atroflavescens Lynge

Tatry Wysokie: FlaKus $(2007,2014)$.

Rhizocarpon cinereovirens (Müll. Arg.) Vain.

Tatry Wysokie: WĘGRZYN (2008).

Rhizocarpon glaucescens (Th. Fr.) H. Magn.

Tatry Wysokie: FlaKUS $(2007,2014)$.

Rhizocarpon sublavatum Fryday

Tatry Wysokie: Matura i in. (2017), Matura (2020).

Rhizocarpon superficiale (Schaer.) Malme

Tatry Wysokie: KuKwa \& FlaKus (2009), FlaKus (2014).

Rhizocarpon timdalii Ihlen \& Fryday

Pogórze Spisko-Gubałowskie: MATwIEJuk (2011).

Rinodina griseosoralifera Coppins

Gorce: CZARnota \& KuKWA (2007); Beskid Niski: BIELCZYK i in. (2016).

* Roselliniopsis tartaricola (Nyl. ex Leight.) Matzer

Gorce: KuKWA \& CZARNOTA (2006).

* Sagediopsis fissurisedens Hafellner

Tatry Wysokie: KuKWA \& Flakus (2009).

Sarcogyne clavus (DC.) Kremp.

Gorce: CZARNOTA \& WoJNAROWICZ (2008).

Schadonia fecunda (Th. Fr.) Vězda \& Poelt

Tatry Wysokie: Flakus (2006b, 2007, 2014).

${ }^{*}$ Sclerococcum australe (Triebel \& Hertel) Ertz \& Diederich

Syn.: Dactylospora australis Triebel \& Hertel

Tatry Wysokie: Kukwa \& Flakus (2009).

*Sclerococcum deminutum (Th. Fr.) Ertz \& Diederich

Syn.: Dactylospora deminuta (Th. Fr.) Triebel

Tatry Wysokie: KuKwa \& Flakus (2009).

${ }^{*}$ Sclerococcum purpurascens (Triebel) Ertz \& Diederich

Syn.: Dactylospora purpurascens Triebel

Gorce: KuKwa \& CZARnota (2006), CZARnota \& WojnAROWicz (2008).

Scoliciosporum sarothamni (Vain.) Vězda

Gorce: Czarnota \& Wojnarowicz (2008); Pogórze Przemyskie: KościelniaK \& Baran (2018); Beskid

Niski: BIELCZYK i in. (2016); Rów Podtatrzański: ŚlıwA \& KuKwa (2012); Tatry Zachodnie: Śliwa \& KuKwa (2012); Bieszczady Zachodnie: KościelniaK (2013), KAPEK (2014).

* Scutula miliaris (Wallr.) P. Karst.

Beskid Żywiecki: MiąDliKowsKa \& Alstrup (1995), MiąDliKowsKa (1999).

Scytinium imbricatum (P.M. Jørg.) Otálora, P.M. Jørg. \& Wedin

Syn.: Leptogium imbricatum P.M. Jørg.

Tatry Wysokie: FlaKus $(2007,2014)$. 
${ }^{*}$ Skyttea gregaria Sherwood, D. Hawksw. \& Coppins

Gorce: KuKWA \& CZARNOTA (2006).

Solorina bispora Nyl. var. bispora

Tatry Zachodnie: FlaKus (2007); Tatry Wysokie: FlaKus (2007, 2014).

Solorina bispora var. macrospora (Harm.) H. Olivier

Tatry Wysokie: Flakus (2006b, 2007, 2014).

Solorina octospora Arnold

Tatry Wysokie: FlaKus $(2007,2014)$.

* Sphaerellothecium atryneae (Arnold) Cl. Roux \& Triebel

Tatry Wysokie: KuKwa \& FlaKus (2009).

* Sphaerellothecium cladoniae (Alstrup \& Zhurb.) Hafellner

Tatry Wysokie: KuKWA \& Flakus (2009).

* Sphaerellothecium contextum Triebel

Tatry Wysokie: KuKWA \& FlakUs (2009).

* Sphinctrina anglica Nyl.

Pieniny: KuKwA i in. (2010).

*Spirographa aff. ciliata (Kalb) Flakus, Etayo \& Miądl.

Syn.: Cornutispora aff. ciliata Kalb

Tatry Wysokie: KuKWA \& FLAKUS (2009).

* Spirographa fusisporella (Nyl.) Zahlbr.

Tatry Wysokie: KuKWA \& FlaKus (2009).

Staurothele bacilligera (Arnold) Arnold

Tatry Zachodnie: Śliwa \& KrZewicka (2012b); Tatry Wysokie: Flakus \& BielczYK (2006), Flakus (2007, 2014).

Stereocaulon botryosum Ach.

Tatry Zachodnie: OSET (2014).

Stereocaulon evolutum Graewe

Tatry Wysokie: FlakUs (2007, 2014), OSET (2014).

Stereocaulon saxatile f. saxatile $\mathrm{H}$. Magn.

Tatry Zachodnie: OSET (2014).

Stereocaulon subcoralloides (Nyl.) Nyl.

Tatry Wysokie: OSET (2014).

* Stigmidium cladoniicola Zhurb. \& Diederich

Tatry Wysokie: KuKwa \& Flakus (2009).

* Stigmidium clauzadei Cl. Roux \& Nav.-Ros.

Gorce: KuKWA \& CZARNOTA (2006).

* Stigmidium frigidum (Th. Fr. ex Sacc.) Alstrup \& D. Hawksw.

Tatry Wysokie: KuKWA \& FlaKus (2009).

* Stigmidium fuscatae (Arnold) R. Sant.

Gorce: CZARnota \& WojnARowicz (2008), Kukwa \& JABŁoŃSKa (2008); Beskid Niski: KuKWA (2005b), BIELCZYK i in. (2016).

* Stigmidium gyrophorarum (Arnold) D. Hawksw.

Tatry Wysokie: KuKwa \& Flakus (2009). 
${ }^{*}$ Stigmidium leprariae Zhurb.

Tatry Wysokie: KuKwa \& Flakus (2009).

* Stigmidium mycobilimbiae $\mathrm{Cl}$. Roux, Triebel \& Etayo

Gorce: Czarnota \& Kunwa (2004); Tatry Zachodnie: Kukwa (2005b), Kukwa \& Czarnota (2006);

Tatry Wysokie: Flakus (2007, 2014), KuKWA \& FlaKUs (2009).

* Stigmidium pseudopeltideae $\mathrm{Cl}$. Roux \& Triebel

Tatry Wysokie: MiąDLIKOWSKA (1999).

* Stigmidium schaereri (A. Massal.) Trevis

Beskid Śląski: StaRmaCHOWA \& KISZKA (1965).

* Stigmidium squamariae (B. de Lesd.) Cl. Roux \& Triebel

Gorce: KuKWA \& CZARNOTA (2006).

Strigula glabra (A. Massal.) V. Wirth

Bieszczady Zachodnie: KisZKA \& KoŚCIELNIAK (2002), KośCIELNIAK (2013).

* Taeniolella atricerebrina Hafellner

Tatry Wysokie: KuKwa \& FlaKus (2009).

* Taeniolella trapeliopseos Diederich

Beskid Żywiecki: Kukwa i in. (2010); Tatry Wysokie: Czarnota (2012).

*Talpapellis beschiana (Diederich) Zhurb., U. Braun, Diederich \& Heuchert

Syn.: Taeniolella beschiana Diederich

Gorce: Kukwa \& Kowalewska (2007), Czarnota \& Wojnarowicz (2008), KuKwa i in. (2010); Beskid

Sądecki: Kukwa \& Kowalewska (2007), Kukwa \& JabŁońsKa (2008); Rów Podtatrzański: Kukwa \& FlaKus (2009).

Tetramelas chloroleucus (Körb.) A. Nordin

Tatry Wysokie: CZARNOTA \& TANONA (2020).

Tetramelas papillatus (Sommerf.) Kalb

Syn: Buellia papillata (Sommerf.) Tuck

Tatry Wysokie: FlaKus (2004, 2007, 2014).

Thelenella muscorum var. octospora (Nyl.) Coppins \& Fryday

Tatry Wysokie: Flakus \& KuKwa (2009), FlaKus (2014).

Thelidium athallinum Servít

Tatry Zachodnie: ŚLIwA \& KRZEWICKA (2012b); Bieszczady Zachodnie: KrZEWICKA i in. (2017).

Thelidium circumspersellum (Nyl.) Zschacke

Beskid Sądecki: MAtura i in. (2017), Matura (2020).

Thelidium klementii Servít

Beskid Żywiecki: Matura i in. (2017); Beskid Sądecki: MAtura i in. (2017).

Thelidium olivaceum (Schaer.) Körb.

Pieniny: KiszKa (2004, 2005); Bieszczady Zachodnie: KISZKA \& KościelniaK (2004, 2005); Tatry Wysokie: FlaKus (2007).

Thelidium pluvium Orange

Beskid Makowski: Matura i in. (2017), Matura (2020); Bieszczady Zachodnie: KrZEwicka i in. (2017).

Thelidium rehmii Zschacke

Beskid Makowski: Matura i in. (2017), Matura (2020); Gorce: Matura i in. (2017), Matura (2020); Beskid Sądecki: Matura i in. (2017), Matura (2020); Gorce: Matura i in. (2017); Beskid Niski: Matura i in. (2017), Matura (2020); Pieniny: Matura i in. (2017), Matura (2020). 
Thelidium submethorium (Vain.) Zschacke

Tatry Wysokie: MATURA (2016, 2020).

Thelidium velutinum (Bernh.) Körb.

Bieszczady Zachodnie: KIsZKA \& KoŚCIELNIAK (2004).

${ }^{*}$ Thelocarpon epibolum var. epithallinum (Leight.) G. Salisb.

Gorce: MiądLIKowsKa \& ALSTRUP (1995).

Thelocarpon olivaceum B. de Lesd.

Bieszczady Zachodnie: KISZKA \& KoŚCIELNIAK (2004).

Thelocarpon sphaerosporum $\mathrm{H}$. Magn.

Tatry Wysokie: FlaKus $(2007,2014)$.

Toensbergia leucococca (R. Sant.) Bendiksby \& Timdal

Syn.: Pycnora leucococca (Vain.) R. Sant.

Beskid Żywiecki: KuKwa \& KuBIAK (2007).

Toninia coelestina (Anzi) Vězda

Tatry Wysokie: FlaKus $(2007,2014)$.

Trapeliopsis glaucolepida (Nyl.) Gotth. Schneid.

Beskid Żywiecki: CZarnota \& Węgrzyn (2012); Gorce: CZarnota \& Wojnarowicz (2008); Tatry Zachodnie: ŚlIwA \& KuKwA (2012); Tatry Wysokie: CZARnota \& KuKWA (2004).

${ }^{*}$ Tremella lichenicola Diederich

Beskid Żywiecki: Kukwa i in. (2010); Gorce: Kunwa \& CZARnota (2006), Kukwa i in. (2010); Tatry Zachodnie: CZARnota (2012); Tatry Wysokie: CZARnota (2012).

* Tremella phaeophysciae Diederich \& M.S. Christ.

Beskid Niski: KuKWA (2005b), BIELCZYK i in. (2016).

${ }^{*}$ Trichonectria hirta (A. Bloxam) Petch

Beskid Wyspowy: Kukwa \& CZARnota (2006).

Umbilicaria lyngei Schol.

Tatry Wysokie: KRZEWICKA (2004).

Umbilicaria maculata Krzewicka, M.P. Martín \& M.A. García

Tatry Wysokie: KRZEWICKA i in. (2009), FlaKus (2014).

Umbilicaria rhizinata (Frey \& Poelt) Krzewicka

Tatry Wysokie: KrzEWICKA (2010).

Umbilicaria cf. umbilicarioides (Stein) Krog \& Swinscow

Tatry: KRZEWICKA i in. (2009).

Variospora dolomiticola (Hue) Arup, Søchting \& Frödén

Syn.: Caloplaca dolomiticola (Hue) Zahlbr.

Kotlina Żywiecka: WiLK (2012); Gorce: WILK (2012); Pogórze Przemyskie: KoŚCIELNIAK \& BARAN (2018); Kotlina Jasielsko-Krośnieńska: StolarczyK (2009); Pieniny: KisZKa (2004, 2005); Tatry Zachodnie: WILK (2012).

Uwaga: We wcześniejszej literaturze Caloplaca dolomiticola potraktowano jako synonim Caloplaca velana (A. Massal.) Du Rietz (por. BIELCZYK 2003).

Verrucaria acrotella Ach.

Beskid Mały: Matura (2020); Gorce: Matura (2020); Beskid Sądecki: Matura (2020); Beskid Niski: BIELCZYK i in. (2016). 
Verrucaria cataleptoides (Nyl.) Nyl.

Gorce: KrZewicka (2012); Pieniny: KrZewicka (2012), Matura (2020); Tatry Zachodnie: KrZewickA (2012), ŚLIWA \& KRZEWicka (2012a), Matura (2020).

Uwaga: Gatunek podany z Tatr przez Mотүке (1927), potraktowany został jako synonim Verrucaria aethiobola Wahlenb. (BIELCZYK 2003).

Verrucaria cernaensis Zschacke

Bekid Żywiecki: Krzewicka (2012), Matura (2020); Gorce: Krzewicka (2012), Matura (2020); Beskid Sądecki: KrZewicka (2012), Matura (2020); Pogórze Przemyskie: Krzewicka (2012), Matura (2020); Beskid Niski: KrZewicka (2012), Matura (2020); Tatry Wysokie: KrZewicka (2012), FlaKus (2014); Bieszczady Zachodnie: KościelniaK (2013), KRZEWICKA i in. (2017).

Verrucaria cincta Hepp

Pieniny: KRZEWICKA (2012); Bieszczady Zachodnie: KRZEwICKA i in. (2017).

Verrucaria devensis (G. Salisb.) Orange

Beskid Mały: Matura i in. (2017), Matura (2020); Beskid Makowski: Matura i in. (2017), Matura (2020); Beskid Sądecki: Matura i in. (2017), Matura (2020).

Verrucaria elaeomelaena (A. Massal.) Arnold

Beskid Makowski: KrZewicka (2012), Matura (2020); Beskid Żywiecki: Krzewicka (2012), Matura (2020); Beskid Sądecki: Matura \& Krzewicka (2015), Matura (2020); Beskid Niski: KrzewickA (2009a, 2012), BielczyK i in. (2016), Matura (2020); Pieniny: KrZeWicka \& KisZKa (2007), KrzeWickA (2012); Pogórze Spisko-Gubałowskie: MAtura (2020); Tatry Zachodnie: KrZEwICKA \& KISZKA (2007), KRZEWICKA (2012); Bieszczady Zachodnie: KRZEWICKA (2012).

\section{Verrucaria humida Orange}

Syn.: Verrucaria andesiatica sensu auct. pl.

Beskid Mały: Matura (2000); Beskid Wyspowy: Matura (2000); Gorce: Matura (2000); Beskid Sadecki: Matura (2000); Pogórze Przemyskie: Matura (2000); Tatry Zachodnie: Krzewicka (2012), Matura (2000); Tatry Wysokie: Flakus (2007); Bieszczady Zachodnie: KRZEwICKA (2012).

\section{Verrucaria hydrophila Orange}

Syn.: Verrucaria denudata Zschacke nom. illeg. non Nyl., Verrucaria hydrela auct., Verrucaria hydrela Ach.

Beskid Mały: Krzewicka (2012); Beskid Makowski: KrZewicka (2012); Beskid Żywiecki: KrzewickA (2012); Gorce: Czarnota i in. (2005), CZarnota (2010), Krzewicka (2012); Beskid Sądecki: Matura \& Krzewicka (2015); Pogórze Rożnowskie: Krzewicka (2012); Pogórze Przemyskie: KościelniaK \& Baran (2018); Beskid Niski: KrzeWicka (2009a), BIelCZYK i in. (2016); Pieniny: KisZKa (2005); Tatry Zachodnie: KrZewicka (2012); Tatry Wysokie: Flakus (2007, 2014), KrZEWICKA (2012); Bieszczady Zachodnie: KościelniaK \& KiszKa (2005), KrZewicka (2012), KościelniaK (2013), KrzeWickA i in. (2017).

\section{Verrucaria maculiformis Kremp.}

Syn.: Verrucaria subdolosa auct. sensu pol.

Beskid Sądecki: Matura (2020); Pogórze Przemyskie: Krzewicka (2012), Matura (2020); Kotlina Orawsko-Nowotarska: KRZEWICKA (2012); Tatry Zachodnie: KRZEWICKA (2012); Bieszczady Zachodnie: KRZEWICKA (2012).

Verrucaria madida Orange

Beskid Mały: Krzewicka (2012), Matura (2020); Beskid Wyspowy: Krzewicka(2012), Matura (2020).

Verrucaria ochrostoma Borrer

Gorce: KRZEWICKA (2012); Pieniny: KRZEWICKA (2012).

Verrucaria pinguicula A. Massal.

Pieniny: KrZewicka (2012); Tatry Zachodnie: KrZewicKa (2012), Śliwa \& KrZEWICKA (2012b). 
Verrucaria policensis Servít

Beskid Niski: BIELCZYK i in. (2016).

Verrucaria tectorum (A. Massal.) Körb.

Pogórze Wiśnickie: Śliwa (2010); Bekid Sądecki (Matura 2020); Beskid Niski: BIElCZYK i in. (2016); Tatry Zachodnie: KrZEWICKA (2012); Tatry Wysokie: FlaKus (2007, 2014).

Verrucaria umbrinula Nyl.

Beskid Makowski: Matura (2020); Beskid Niski: Krzewicka (2009a), KrZewicKa (2012); Bieszczady Zachodnie: KrZewicka i in. (2017); Tatry Wysokie: KrZewicka (2012), Flakus (2014), Matura (2020).

Verrucaria viridigrana Breuss

Pogórze Przemyskie: CZARnOTA i in. (2018).

Verrucula elegantaria (Zehetl.) Nav.-Ros. \& Cl. Roux

Pieniny: KRZEWICKA (2012); Tatry Wysokie: KRZEWICKA (2012).

Verrucula helvetica (B. de Lesd.) Nav.-Ros. \& Cl. Roux

Pieniny: KRZEWICKA (2012).

Vezdaea rheocarpa Poelt \& Döbbeler

Bieszczady Zachodnie: MiądLIKOWSKA \& ALSTRUP (1995).

${ }^{*}$ Vouauxiella lichenicola (Linds.) Petr. \& Syd.

Pogórze Wiśnickie: Śliwa (2010); Beskid Makowski: KuKWa \& JabŁońsKa (2008); Gorce: KuKWA \& CZARnota (2006); Beskid Niski: KuKwa (2005b), BiElCZYK i in. (2016); Góry Sanocko-Turczańskie: KUKWA \& CZARNOTA (2006).

"Vouauxiomyces truncatus (B. de Lesd.) Dyko \& D. Hawksw.

Beskid Niski: KuKwa (2005b), CZYŻEwsKa i in. (2008).

Xanthocarpia crenulatella (Nyl.) Frödén, Arup \& Søchting

Syn.: Caloplaca crenulatella (Nyl.) H. Olivier

Pogórze Śląskie: WILK (2012); Beskid Mały: WILK (2012); Kotlina Żywiecka: WILK (2012); Pogórze Przemyskie: KośCIELNIAK \& BARAN (2018); Pogórze Spisko-Gubałowskie: WILK (2012); Beskid Niski: BIELCZYK i in. (2016); Kotlina Orawsko-Nowotarska: WILK (2012); Pieniny: WILK (2012); Tatry Zachodnie: WILK (2012).

Xanthocarpia interfulgens (Nyl.) Frödén, Arup \& Søchting

Syn.: Caloplaca interfulgens (Nyl.) J. Steiner

Pieniny: WILK (2015); Tatry Zachodnie: WILK (2015).

Xanthocarpia marmorata (Bagl.) Frödén, Arup \& Søchting

Syn.: Caloplaca marmorata (Bagl.) Jatta

Pieniny: WILK $(2011,2012)$.

Xanthoparmelia angustiphylla (Gyeln.) Hale

Beskid Mały: KanigowsKI i in. (2016); Beskid Wyspowy: KANIGOwsKI i in. (2016); Gorce: KanigowsKI $\mathrm{i}$ in. (2016); Beskid Sądecki: KANIGOWSKI i in. (2016); Beskid Niski: KANIGOwSKI i in. (2016); Bieszczady Zachodnie: KANIGOWSKI i in. (2016).

Xanthoparmelia aff. cumberlandia (Gyeln.) Hale

Gorce: KANIGOWSKI i in. (2016); Pogórze Przemyskie: KANIGOwsKI i in. (2016).

Xanthoparmelia plittii (Gyeln.) Hale

Gorce: KANIGOWSKI i in. (2016); Pogórze Przemyskie: KANIGOwski i in. (2016); Pogórze Spisko-Gubałowskie: KANIGOWSKI i in. (2016); Bieszczady Zachodnie: KANIGOWSKI i in. (2016).

*Xanthoriicola physciae (Kalchbr.) D. Hawksw.

Pieniny: KuKWA \& FlakUS (2009). 
${ }^{*}$ Zwackhiomyces berengerianus (Arnold) Grube \& Triebel

Tatry Wysokie: KuKWA \& Flakus (2009).

${ }^{*}$ Zwackhiomyces diederichii D. Hawksw. \& Iturr.

Bieszczady Zachodnie: KUKWA \& FlaKus (2009).

* Zwackhiomyces peltigerae Miądl. \& Alstrup

Gorce: MiądlikowsKa \& Alstrup (1995).

\section{Gatunki wyłączone z listy porostów polskich Karpat}

Abrothallus parmeliarum (Sommerf.) Arnold - błędna identyfikacja, okaz cytowany przez REHMANA (1879) i BobERSKIEGo (1886) jako Abrothallus smithii (Tul.) (nazwa będąca synonimem A. parmeliarum) reprezentuje A. peyritschii (Stein) Kotte (CZYŻEWSKA \& KUKWA 2009).

Arthonia exilis (Flörke) Anzi - błędna identyfikacja, okazy cytowane przez CZARNOTĘ (2000) reprezentują Bryostigma muscigenum (Th. Fr.) Frisch \& G. Thor i prawdopodobnie Arthonia didyma Körb. (CZARNOTA 2010).

Arthonia fuliginosa (Turner \& Borrer) Flot. - błędna identyfikacja, okaz cytowany przez CzARNOTE (2000) reprezentuje Felipes leucopellaeus (Ach.) Frisch \& G. Thor; syn.: Arthonia leucopellaea (Ach.) Almq. (CZARNOTA 2010).

Bacidia auerswaldii (Hepp ex Stizenb.) Mig. - błędna identyfikacja, okaz cytowany przez BIELCZYK (2003) nie reprezentuje rodzaju Bacidia; pozostał niezidentyfikowany.

Bacidia friesiana (Hepp) Körb. - dane ToBolEwsKIEGo (1965) wątpliwe, weryfikacja niemożliwa z powodu braku okazów zielnikowych.

Bacidia viridula Erichsen - błędna identyfikacja, okaz cytowany przez NowAKA (1998a) reprezentuje Bellicidia incompta (Borrer) Kistenich, Timdal, Bendiksby \& S. Ekman.

Bagliettoa limborioides A. Massal. - notowanie MотYKI (1927) wątpliwe, weryfikacja niemożliwa z powodu braku okazów zielnikowych (KRZEWICKA 2012).

Brianaria bauschiana (Körb.) S. Ekman \& M. Svensson - błędna identyfikacja, okaz cytowany przez KISZKĘ i KoŚCIELNIAKa (2001) pod synonimiczną nazwą Micarea bauschiana (Körb.) V. Wirth \& Vězda reprezentuje Psilolechia clavulifera (Nyl.) Coppins (CZARnota 2007a).

Bryoria crispa (Motyka) Bystrek - synonim Bryoria fuscescens (Gyeln.) Brodo \& D. Hawksw.

Bryoria setacea (Ach.) Brodo \& D. Hawksw. - synonim Bryoria capillaris (Ach.) Brodo \& D. Hawksw.

*Chaenothecopsis gracilis Nádv. - błędna identyfikacja, okaz cytowany przez CZARNOTĘ (2000) reprezentuje Mycocalicium subtile (Pers.) Szatala (CZARnota 2010).

Cladonia bacilliformis (Nyl.) Sarnth. - błędna identyfikacja, okazy cytowane przez AlstRUPA i OLECH (1992a, b) reprezentują Cladonia cenotea (Ach.) Schaer. i Cladonia ramulosa (With.) J.R. Laundon (OsYCZKA 2011).

Cladonia cyanipes (Sommerf.) Nyl. - błędna identyfikacja, rewizja okazów (por. BIELCZYK 2003) nie potwierdziła występowania tego gatunku w Polsce (OSYCZKA 2011).

Cladonia stricta (Nyl.) Nyl. - notowania pod tą nazwą (por. BIELCZYK 2003) są wynikiem błędnej interpretacji synonimów, faktycznie odnoszą się do Cladonia trassii Ahti (FLAKus 2014).

Lecanora cadubriae (A. Massal.) Hedl. - błędna identyfikacja, zrewidowane okazy (por. BIELCZYK 2003) dotyczą Palicella filamentosa (Stirt.) Rodr. Flakus \& Printzen i Lecanora phaeostigma (Körb.) Almb. (CZARnota i in. 2010). 
Lecanora concolor Ramond - błędna identyfikacja, cytowany okaz (BIELCZYK 2003) nie reprezentuje tego gatunku, pozostał niezidentyfikowany.

Lecanora conferta (Duby ex Fr.) Grognot - notowanie KISZKI i SzELĄGA (1992) oraz KISZKI (2000) wątpliwe, weryfikacja niemożliwa z powodu braku okazów zielnikowych.

Lecanora gangaleoides Nyl. - notowanie RYDZAKA (1955) wątpliwe, weryfikacja niemożliwa z powodu braku okazów zielnikowych.

Lecanora hypopta Ach. - błędna identyfikacja, okazy cytowane przez CZARNOTĘ i in. (2005) reprezentują Lecanora phaeostigma (Körb.) Almb. (CZARnota 2010).

Lecanora leuckertiana Zedda - błędna identyfikacja, zrewidowane okazy (por. BIELCZYK 2003) reprezentują Lecanora compallens Herk \& Aptroot i Lepraria ecorticata (J.R. Laundon) Kukwa (Kukwa 2006).

Lecanora marginata (Schaer.) Hertel \& Rambold - gatunek nieudokumentowany materiałem zielnikowym w polskiej części Karpat (FLAKUS 2014).

Lecidea gibberosa Th. Fr. - błędna identyfikacja, okaz cytowany przez BIELCZYK (2003) nie reprezentuje tego gatunku, pozostał niezidentyfikowany.

Lecidea meiocarpoides Nyl. - synonim Micarea lithinella (Nyl.) Hedl.

Melanelia commixta (Nyl.) A. Thell - gatunek niepotwierdzony w Karpatach, zrewidowane okazy (por. BIELCZYK 2003) reprezentują Melanelia agnata (Nyl.) A. Thell (SzCZEPAŃSKa \& KossowsKa 2017).

Micarea assimilata (Nyl.) Coppins - błędna identyfikacja, okazy cytowane przez ToBolEwsKIEGO (1959) pod synonimiczną nazwą Lecidea assimilata Nyl. reprezentują Micarea incrassata Hedl.; pozostałe notowania z polskich Karpat (por. BIELCZYK 2003) odnoszą się do Helocarpon crassipes Th. Fr. (CZARNOTA 2007a).

Micarea ternaria (Nyl.) Vězda - błędna identyfikacja, okaz cytowany przez AlsTRUPA i OLECH (1990, 1992a) reprezentuje Micarea lignaria (Ach.) Hedl. (CZARNOTA 2007a).

Ochrolechia tartarea (L.) A. Massal. - błędna identyfikacja, okaz cytowany przez CZARNOTE (2000) reprezentuje gatunek z rodzaju Vericellaria, prawdopodobnie V. lactea (L.) I. Schmitt \& Lumbsch (CzARNOTA 2010).

Physcia wainioi Räsänen - synonim Physcia caesia var. caesiella (B. de Lesd.) Clauzade \& Cl. Roux.

Polyblastia bryophila Lönnr. - brak udokumentowanych stanowisk tego gatunku w polskiej części Tatr (FlaKus 2014).

Porpidia flavicunda (Ach.) Gowan - gatunek niepotwierdzony w Polsce (JABŁOŃSKA 2012).

Porpidia rugosa (Taylor) Coppins \& Fryday - okazy z Karpat podane pod synonimiczną nazwą Porpidia glaucophaea (Körb.) Hertel \& Knoph (por. BIELCZYK 2003) reprezentują inne gatunki z rodzaju Porpidia (JABŁOŃSKA 2012).

Ramalina polymorpha (Lilj.) Ach. - gatunek nieudokumentowany materiałem zielnikowym, notowanie z Tatr (ALSTRUP \& OLECH 1992b) wątpliwe.

Rinodina dubyana (Hepp) J. Steiner - gatunek niepotwierdzony w Polsce (NowAK 1998b); podany błędnie z Pienin (KiszKa 2000) oraz wątpliwie z Tatr (AlstruP \& Olech 1992b).

Rinodina efflorescens Malme - gatunek błędnie podany przez BIELCZYK (2003) z polskich Karpat.

* Sclerococcum parasiticum (Flörke) Ertz \& Diederich; syn.: Dactylospora parasitica (Florke) Zopf - błędna identyfikacja, okazy cytowane przez CZARNOTE (2000) należą do Tremella lichenicola Diederich (CZARNOTA 2010).

Scytinium subtile (Schrad.) Otálora, P.M. Jørg. \& Wedin - błędna identyfikacja, okaz cytowany przez CZARNote (2000) pod synonimiczną nazwą Leptogium subtile (Schrader) Torss. reprezentuje Parmeliella triptophylla (Ach.) Müll. Arg. (CZARnota 2010). 
Stereocaulon spathuliferum Vain. - gatunek niepotwierdzony z obszaru Polski (OSET 2014).

Thelidium scrobiculare (Garov.) Arnold - synonim Thelidium decipiens (Nyl.) Kremp.

Verrucaria andesiatica Servít - wszystkie tak oznaczone okazy z Polski (por. BIELCZYK 2003, KRzEwICKA 2012) reprezentują Verrucaria humida Orange (Thus i in. 2015).

Verrucaria barrandei Sérvít - gatunek niepotwiedzony z obszaru Polski, zrewidowane okazy reprezentują Verrucaria cataleptoides (Nyl.) Nyl. i V. ochrostoma Borrer (KrZEWICKA 2012).

Verrucaria crassiuscula Sérvít - błędna identyfikacja, okazy cytowane przez KISZKE (1997a, b) reprezentują Bagliettoa calciseda (DC.) Gueidan \& Cl. Roux i Thelidium sp. (KrZEwICKA 2012).

Verrucaria funckiana Sérvít - błędna identyfikacja, zrewidowany okaz reprezentuje Verrucaria nigrescens f. tectorum (A. Massal) Coppins \& Aptroot (KRZEWICKA 2012).

Verrucaria koerberi Hepp - gatunek podany przez NowAKA i TOBOLEWSKIEGO (1975) jako Amphoridium koerberi (Hepp) Arnold; niepotwierdzony w Polsce, weryfikacja niemożliwa z powodu braku okazów zielnikowych (KRZEWICKA 2012).

Verrucaria mortarii Lamy - notowanie z Tatr ALSTRUPA i OLECH (1990) niepotwierdzone, weryfikacja niemożliwa z powodu braku okazów zielnikowych (KRZEWICKA 2012).

Verrucaria pulicaris A. Massal. - gatunek niepotwierdzony w Polsce, weryfikacja niemożliwa z powodu braku okazów zielnikowych (KRZEWICKA 2012).

Verrucaria pustulifera Servít - notowanie KISZKI i PIÓRECKIEGO (1992) błędne, zrewidowany okaz reprezentuje Placopyrenium (KRZEWICKA 2012).

Verrucaria velana (A. Massal.) Zahlbr. - błędna identyfikacja, zrewidowane okazy reprezentują Verrucaria macrostoma Dufour ex DC. (KRZEWICKA 2012).

Xanthoparmelia loxodes (Nyl.) O. Blanco, A. Crespo, Elix, D. Hawksw. \& Lumbsch; syn.: Neofuscelia loxodes (Nyl.) Essl. - błędna identyfikacja okazów (por. BIELCZYK 2003), gatunek dotychczas nieudokumentowany w Karpatach (SZCZEPAŃSKA \& KosSOwSKA 2014).

Xanthoparmelia pulla (Ach.) O. Blanco, A. Crespo, Elix, D. Hawksw. \& Lumbsch; syn.: Neofuscelia pulla (Ach.) Essl. - błędna identyfikacja okazów (por. BIELCZYK 2003), gatunek dotychczas nieudokumentowany w Karpatach (SZCZEPAŃSKA \& KosSOWSKA 2014).

Podziękowania. Autorzy serdecznie dziękują Dr hab. Beacie Krzewickiej za uwagi dotyczące gatunków rodzaju Verrucaria s.l. oraz Dr Karinie Wilk za konsultacje w kwestii rodzaju Caloplaca s.l., a także Recenzentom za cenne uwagi dotyczące ostatnich zmian nomenklaturowych. Za udostępnienie brakującej literatury dziękujemy Prof. Martinowi Kukwie. Praca została częściowo sfinansowana ze środków subwencyjnych przyznanych przez MNiSW dla Instytutu Botaniki im. W. Szafera Polskiej Akademii Nauk.

\section{LITERATURA}

Alstrup V. 2004. New records in distribution of lichens and lichenicolous fungi. - Graphis Scripta 16(2): $46-57$.

Alstrup V. \& Olech M. 1990. Additions to the lichen flora of the Polish Tatra Mountains. II. - Zeszyty Naukowe Uniwersytetu Jagiellońskiego, Prace Botaniczne 21: 211-217.

Alstrup V. \& Olech M. 1992a. Additions to the lichen flora of the Polish Tatra Mountains. III. - Zeszyty Naukowe Uniwersytetu Jagiellońskiego, Prace Botaniczne 24: 179-184.

Alstrup V. \& Olech M. 1992b. Checklist of the lichens of the Tatra National Park, Poland. - Zeszyty Naukowe Uniwersytetu Jagiellońskiego, Prace Botaniczne 24: 185-206. 
Bayerova Š., Kukwa M. \& Fehrer J. 2005. A new species of Lepraria (lichenized Ascomycetes) from Europe. - Bryologist 108(1): 131-138.

BIELCZYK U. 2003. The lichens and allied fungi of the Polish Western Carpathians. - W: U. BIELCZYK (red.), The lichens and allied fungi of the Polish Carpathians - an annotated checklist. Biodiversity of the Polish Carpathians. 1, s. 23-232. W. Szafer Institute of Botany, Polish Academy of Sciences, Kraków.

BielCZYK U. (red.). 2003. The lichens and allied fungi of the Polish Carpathians - an annotated checklist. Biodiversity of the Polish Carpathians. 1, s. 342. W. Szafer Institute of Botany, Polish Academy of Sciences, Kraków.

BielczyK U., Lackovičová A., FARKas E. E., LÖKÖs L., LišKa J., Breuss O. \& KondRATYUK S. YA. 2004. Checklist of lichens of the Western Carpathians. Biodiversity of the Carpathians. 1. s. 181. W. Szafer Institute of Botany, Polish Academy of Sciences, Kraków.

Bielczyk U., Czarnota P., Kukwa M., Śliwa L. Kościelniak R., Betleja L., Kozik R., Krzewicka B., HachuŁKa M., Adamska E., Węgrzyn M., Bielec D., Flakus A., GuZow-Krzemińska B., Kolanko K., Kozik J., Leśniański G., Lisowska M., Oset M., OsyczKa P., PietrzykowskaUrban K., Sadowska-Deś A., SŁaby A., Studzińska-Sroka E., Wilk K., Zaniewski P. T. \& ZARABSKA-BoŻEJEWICZ D. 2016. - Lichens and lichenicolous fungi of Magurski National Park (Poland, Western Carpathians). - Polish Botanical Journal 61(1): 127-160.

BOBERSKI W. 1886. Systematische bersicht der Flechten Galiziens. - Verhhandlungen der Zoologischen-Botanischen Gesellschaft in Wien 36: 243-286.

BREuss O. 2009. A synopsis of the lichen genus Placopyrenium (Verrucariaceae), with description of new taxa and a key to all species. - Bibliotheca Lichenologica 99: 93-112.

Ceynowa-Gietdon M. 2005. New localities of Epigloea bactrospora and E. pleiospora in Poland. - Graphis Scripta 17(2): 52-55.

Cyкоwska B. \& Flakus A. 2005. Epigloea medioincrassata (Epigloeaceae, non-lichenized Ascomycota), a species new to Poland. - Polish Botanical Journal 50(2): 233-234.

Czarnota P. 2000. Porosty Gorczańskiego Parku Narodowego. Cz. I. Wykaz i rozmieszczenie gatunków. - Parki Narodowe i Rezerwaty Przyrody 19(1): 3-73.

CZarnota P. 2004. New and some rare species of the genus Micarea (Micareaceae) in the lichen flora of Poland. - Polish Botanical Journal 49(2): 135-143.

Czarnota P. 2007a. The lichen genus Micarea (Lecanorales, Ascomycota) in Poland. - Polish Botanical Studies 23: 1-199.

Czarnota P. 2007b. Lecidea variegatula (Lecanorales, zlichenizowane Ascomycota) nie jest gatunkiem wymarłym w Polsce. - Fragmenta Floristica et Geobotanica Polonica 14(1): 175-181.

Czarnota P. 2009. Japewia tornoensis and further localities of J. subaurifera found in the Carpathians. - Acta Mycologica 44(2): 259-264.

Czarnota P. 2010. Krytyczna lista porostów i grzybów naporostowych Gorców. - Ochrona Beskidów Zachodnich 3: 55-78.

Czarnota P. 2011. Micarea contexta and M. lynceola (lichenized Ascomycota), new for Poland. - Polish Botanical Journal 56(2): 307-313.

CZARnota P. 2012. New record of lichenized and lichenicolous fungi from Tatra National Park (W Carpathians). - W: L. LIPNICKI (red.), Lichen protection - Protected lichen species, s. 287-300. Wydawnictwo Sonar Literacki, Gorzów Wielkopolski.

Czarnota P. 2015. Lecania cuprea and Micarea pycnidiophora (lichenized Ascomycota) new to Poland. - Acta Societatis Botanicorum Poloniae 84(2): 303-307. 
CZARnota P. 2016. Contribution to the knowledge of some poorly known lichens in Poland IV. Bacidia fuscoviridis and Bacidina brandii. - Acta Mycologica 51(1): 1074.

Czarnota P. \& Coppins B. J. 2006. A new Bacidia with long-necked pycnidia from Central Europe. - Lichenologist 38(5): 407-410.

CZarnota P. \& Coppins B. J. 2007. Contribution to the knowledge of rare Bacidia s.lat. (Lecanorales, lichenized Ascomycetes) from Central Europe including a new, pallid forma of Bacidia hemipolia. - Nova Hedwigia 85(3-4): 503-513.

Czarnota P. \& Guzow-Krzemińska B. 2010. A phylogenetic study of the Micarea prasina group shows that Micarea micrococca includes three distinct lineages. - Lichenologist 42(1): 7-21.

CZARnota P. \& GuZow-KRZEMIŃsKa B. 2012. ITS rDNA data confirm a delimitation of Bacidina arnoldiana and B. sulphurella and support a description of a new species within the genus Bacidia. - Lichenologist 44(6): 743-755.

CZArnota P. \& GuZow-KrZemińska B. 2018. Bacidina mendax sp. nov., a new widespread species in Central Europe, together with a new combination within the genus Bacidina. - Lichenologist 50(1): 43-57.

CZarnota P. \& Hernik E. 2013a. Mniaecia jungermaniae and Puttea margaritella (lichenized Ascomycota) found in Poland. - Acta Societatis Botanicorum Poloniae 82(2): 175-179.

Czarnota P. \& Hernik E. 2013b. Notes on two lichenicolous Epigloea species from Central Europe. Acta Societatis Botanicorum Poloniae 82(4): 321-324.

Czarnota P. \& Kukwa M. 2004. Some sorediate lichens and lichenicolous fungi new to Poland. - Graphis Scripta 15(1-2): 24-32.

Czarnota P. \& Kukwa M. 2006 (2007). Lichenes Poloniae Exsiccati. Fasc. III (Nos. 51-75). - Acta Botanica Cassubica 6: 179-188.

Czarnota P. \& Kunwa M. 2007. Rinodina griseosoralifera, a lichen species new to the Western Carpathians. - Acta Mycologica 42(2): 287-290.

Czarnota P. \& Tanona M. 2020. Species of lichenized Ascomycota new to Polish Western Carpathians and rare in whole Carpathians. - Folia Cryptogamica Estonica 57: 21-32.

CZarnota P. \& Węgrzyn M. 2012. Lichenized and lichenicolous fungi new to Babia Góra National Park (Poland, Western Carpathians). - Mycotaxon 122: 89-110.

Czarnota P. \& Wojnarowicz A. 2008. Porosty i grzyby naporostowe północnej części grupy Lubania w Gorcach. - Ochrona Beskidów Zachodnich 2: 21-49.

Czarnota P., Flakus A. \& Printzen C. 2009. Lecanora flavoleprosa (Lecanoraceae, lichenized Ascomycota) found in the Carpathians. - Biologia, Bratislava 64(6): 1066-1069.

Czarnota P., Glanc K. \& Nowak J. 2005. Materiały do bioty porostów Gorców ze zbiorów Herbarium Instituti Botanici Polskiej Akademii Nauk w Krakowie. - Fragmenta Floristica et Geobotanica Polonica 12(2): 327-370.

Czarnota P., Mayrhofer H. \& Bobiec A. 2018. Noteworthy lichenized and lichenicolous fungi of opencanopy oak stands in east-central Europe. - Herzogia 31: 172-189.

Czarnota P., Osyczka P. \& KowalewsKa A. 2010. Status of some poorly known lichen species from the genus Lecanora (lichenized Ascomycota) in Poland. - Mycotaxon 113: 449-462.

CZyŻEwska K. \& Kunwa M. 2009. Lichenicolous fungi of Poland. A catalogue and key to species. s. 133. W. Szafer Institute of Botany, Polish Academy of Sciences, Kraków.

CZYŻewska K., HachuŁKa M., ŁUbeK A. \& Zaniewski P. 2008. Distribution of some lichenicolous fungi in Poland. II. - Acta Mycologica 43(2): 193-206. 
Diederich P., PAlice Z. \& ERTZ D. 2008. Cheiromycina ananas is a synonym of Dictyocatenulata alba, a widespread, lichenized, synnematous hyphomycete herewith reported as new for Europe. - Sauteria 15: $205-214$.

Ertz D., Diederich P., Lawrey J., Berger F., Freebury C., Coppins B., Gardiennet A. \& HafellNER J. 2015. Phylogenetic insights resolve Dacampiaceae (Pleosporales) as polyphyletic: Didymocyrtis (Pleosporales, Phaeosphaeriaceae) with Phoma-like anamorphs resurrected and segregated from Polycoccum (Trypetheliales, Polycoccaceae fam. nov.). - Fungal Diversity. 74(1). DOI 10.1007/ s13225-015-0345-6.

Flakus A. 2004. New and rare lichen species of the Polish Tatra Mountains. - Polish Botanical Journal 49(1): 79-91.

Flakus A. 2005. Gyalecta peziza (Gyalectaceae, lichenized Ascomycota), first record in the Polish Tatra Mts. - Biologia, Bratislava 60(4): 373-375.

Flakus A. 2006a. Note on the distribution of some lichenized and lichenicolous fungi of the Tatra National Park. - Acta Mycologica 41(2): 329-342.

Flakus A. 2006b. Three species of lichenized Ascomycota new to Poland. - Biologia, Bratislava 61(1): $15-17$.

FLAKUS A. 2007. Lichenized and lichenicolous fungi from mylonitized areas of the subnival belt in the Tatra Mountains (Western Carpathians). - Annales Botanici Fennici 44: 427-449.

Flakus A. 2014. Porosty piętra turniowego Tatr Polskich, s. 280. Instytut Botaniki im. W. Szafera, Polska Akademia Nauk, Kraków.

Flakus A. \& BielczYK U. 2006. New and interesting records of lichens from the Tatry Mountains. - W: A. Lackovičová, A. Guttová, E. LisickÁ \& P. Lizoñ (red.), Central European lichens. Diversity and threat, s. 271-281. Mycotaxon, Ltd. Ithaca.

Flakus A. \& Kukwa M. 2009. Additions to the biota of lichenized fungi of Poland. - Acta Mycologica 44(2): 247-259.

FlaKuS A. \& Śliwa L. 2012. Additional information on the recently described species, Lecanora printzenii. - Lichenologist 44(4): 561-562.

Frolov I., Vondrák J., Fernández-Mendoza F., Wilk K., Khodosovtsev A. \& Halici M. G. 2016. Three new, seemingly-cryptic species in the lichen genus Caloplaca (Teloschistaceae) distinguished in two-phase phenotype evaluation. - Annales Botanici Fennici 53: 243-262.

Glanc K. \& Tobolewski Z. 1960. Porosty Bieszczadów Zachodnich. - Prace Komisji Biologicznej Poznańskiego Towarzystwa Przyjaciół Nauk 21(4): 1-108.

Glanc K. \& Tobolewski Z. 1965. Lichenotheca Polonica. Fasc. XVIII. Nr. 401-425. Lichenes ex Montibus Gorce. s. 9. Wydawnictwo PAN, Poznań.

Guzow-Krzemińska B., Czarnota P., ŁubeK A. \& Kukwa M. 2016. Micarea soralifera sp. nov., a new sorediate species in the M. prasina group. - Lichenologist 48(3): 161-169.

JabŁońsKa A. 2010. The lichen genus Porpidia in Poland III. - Herzogia 23(2): 217-228.

JABŁoŃSKA A. 2012. Porosty z rodzaju Porpidia Körb. występujące w Polsce. - Monographiae Botanicae 102: 5-123.

JabŁońska A., Oset M. \& Kunwa M. 2009. The lichen family Parmeliaceae in Poland I. The genus Parmotrema. - Acta Mycologica 44(2): 211-222.

Kanigowski P., Flakus A., Oset M., Kowalewska A., Rykaczewski M. \& Kukwa M. 2016. The lichen family Parmeliaceae in Poland. Xanthoparmelia species containing usnic acid. - Herzogia 29(1): 108-119. 
KAPEK N. 2014. Opuszczone wsie w Bieszczadach jako ostoje zagrożonych i chronionych gatunków porostów w Polsce. - Fragmenta Floristica et Geobotanica Polonica 21(1): 147-164.

KIsZKa J. 2000. Porosty (Lichenes). - W: J. Razowski (red.), Fauna i Flora Pienin. - Monografie Pienińskie 1: 55-66.

KISZKa J. 2004. Porosty (Lichenes) rezerwatu Wysokie Skałki w Małych Pieninach (Karpaty Zachodnie). - Chrońmy Przyrodę Ojczystą 60(3): 25-48.

KISZKA J. 2005. Lichens of the Biała Woda Nature Reserve in the Małe Pieniny Mts (Western Carpathians). - Polish Botanical Studies 19: 177-188.

KiszKa J. \& KościelniaK R. 2001. Nowe i rzadkie gatunki porostów (Lichenes) w Bieszczadzkim Parku Narodowym i jego otulinie. Część III. - Roczniki Bieszczadzkie 9: 27-32.

KiszKa J. \& KościelniaK R. 2002. Nowe i rzadkie gatunki porostów (Lichenes) w Bieszczadzkim Parku Narodowym i jego otulinie. Część IV. - Roczniki Bieszczadzkie 10: 253-255.

KiszKa J. \& KośCielniaK R. 2004. Nowe i rzadkie gatunki porostów (Lichenes) w Bieszczadzkim Parku Narodowym i jego otulinie. Część VI. - Roczniki Bieszczadzkie 12: 33-37.

KiszKa J. \& KościelniaK R. 2005. Nowe i rzadkie gatunki porostów (Lichenes) w Bieszczadzkim Parku Narodowym i jego otulinie. Część VII. - Roczniki Bieszczadzkie 13: 245-248.

KIsZKa J. \& PióReCKI J. 1992. Porosty Gór Słonnych w Karpatach Wschodnich, s. 95. Wydawnictwo Zakładu Fizjografii i Arboretum w Bolestraszycach, Bolestraszyce.

KisZKa J. \& Szeląg Z. 1992. Nowe dla Pienin gatunki porostów. - Fragmenta Floristica et Geobotanika 37(2): 597-600.

KnUdSen K. \& Kocourková J. 2008. A study of lichenicolous species of Polysporina (Acarosporaceae). - Mycotaxon 105: 149-164.

KONDRACKI J. 1989. Karpaty. Wyd. 2. s. 261. Wydawnictwo Szkolne i Pedagogiczne, Warszawa.

Kondratyuk S. Ya., Popova L. P., LackovičovÁ A. \& Pišút J. 2003. A catalogue of Eastern Carpathians Lichens. s. 264. M. H. Kholodny Institute of Botany. Kiev - Bratislava.

Kondratyuk S. Ya., Lőkös L., Farkas E., Kärnefelt I., Thell A., Yamamoto Y. \& Hur J.-S. 2020. Three new genera of the Teloschistaceae proved by three gene phylogeny. - Botanica Hungarica 62(1-2): 109-136.

KośCIELNIAK R. 2008. Nowe i rzadkie gatunki porostów (Lichenes) w Bieszczadzkim Parku Narodowym i jego otulinie. Część X. - Roczniki Bieszczadzkie 16: 253-258.

KościelniaK R. 2012. Red list of threatened lichens in the Bieszczady National Park. - W: L. LIPNICKI (red.), Lichen protection - Protected lichen species, s. 301-311. Wydawnictwo Sonar Literacki, Gorzów Wielkopolski.

KościelniaK R. 2013. Porosty Bieszczadzkiego Parku Narodowego - stan obecny i przekształcenia w ostatnim półwieczu. - Lichens of the Bieszczady National Park - present state and changes in the last 50 years. - Monografie Bieszczadzkie 14: 1-602.

Kościelniak R. \& Baran D. 2018. Porosty (grzyby zlichenizowane). - W: M. D. BoćKowski, I. BARA \& R. Michalski (red.), Projektowany Turnicki Park Narodowy: stan walorów przyrodniczych 35 lat od pierwszego projektu parku narodowego na Pogórzu Karpackim, s. 228-239. Fundacja Dziedzictwo Przyrodnicze, Nowosiółki Dydyńskie.

KośCIELniaK R. \& BetLeJa L. 2013. Porosty na nietypowych podłożach antropogenicznych w Bieszczadzkim Parku Narodowym. - Roczniki Bieszczadzkie 21: 35-41.

Kościelniak R. \& KiszKa J. 2003. The lichens and allied fungi of the Polish Eastern Carpathians. - W: U. BIELCZYK (red.), The lichens and allied fungi of the Polish Carpathians - an annotated checklist. 
Biodiversity of the Polish Carpathians 1: 233-294. W. Szafer Institute of Botany, Polish Academy of Sciences, Kraków.

KościelniaK R. \& KiszKa J. 2005. A supplement to the lichen checklist of the Eastern Carpathians. - Roczniki Bieszczadzkie 13: 235-244.

KoŚCielniaK R. \& KisZKa J. 2006. Nowe i rzadkie gatunki porostów (Lichenes) w Bieszczadzkim Parku Narodowym i jego otulinie. Część VIII. - Roczniki Bieszczadzkie 14: 135-138.

Kościelniak R., Betleja L. \& BARAn D. 2016. Multiclavula mucida - epiksyliczny porost naturalnych lasów w Polsce południowo-wschodniej. - Roczniki Bieszczadzkie 24: 47-52.

Kowalewska A. \& Kukwa M. 2007. Cladonia asahinae, a lichen species overlooked in Poland. - Polish Botanical Journal 52: 173-175.

Kowalewska A., Kukwa M., Ostrowska I., JabŁońska A., Oset M. \& SzoK J. 2008. The lichens of the Cladonia pyxidata-chlorophaea group and allied species in Poland. - Herzogia 21: 61-78.

Krzewicka B. 2004. Porosty Hali Gąsienicowej w Tatrach Wysokich. Część I. - Fragmenta Floristica et Geobotanica Polonica 11(2): 365-370.

KrzewickA B. 2009a. Some new records of Verrucaria from Beskid Niski Mts. - Acta Mycologica 44(2): 265-273.

KrZewicka B. 2009b. The "Verrucaria fuscella group" in Poland, with some nomenclatorial remarks. - Acta Societatis Botanicorum Poloniae 78(3): 229-234.

KrzewicKa B. 2010. Umbilicaria rhizinata comb. nov. (lichenized Ascomycota). - Lichenologist 42(4): 491-493.

Krzewicka B. 2012. A revision of Verrucaria s.l. (Verrucariaceae) in Poland. - Polish Botanical Studies 27: 3-143.

Krzewicka B. \& Kiszka J. 2007. Verrucaria elaeomelaena and V. funckii (Verrucariaceae) in Poland. - Polish Botanical Journal 52(2): 125-131.

Krzewicka B., García M. A., Johansen S. D., Sancho L. G. \& Martín M. P. 2009. Morphological and nuclear ribosomal DNA data support distinguishing two new species of Umbilicaria (Umbilicariaceae, Ascomycota) from Europe. - Lichenologist 41(6): 631-648.

Krzewicka B., Smykla J., Galas J. \& Śliwa L. 2017. Freshwater lichens and habitat zonation of mountain streams. - Limnologica 63: 1-10.

Kubiak D. \& Westberg M. 2011. First records of Candelariella efflorescens (Lichenized Ascomycota) in Poland. - Polish Botanical Journal 56: 315-319.

Kubiak D. \& WiLK K. 2016. Caloplaca monacensis (Teloschistaceae, lichenized Ascomycota), a species new to Poland. - Polish Botanical Journal 61(2): 279-281.

Kukwa M. 2004. Porosty z rodzaju Lepraria w Tatrzańskim Parku Narodowym. - Parki Narodowe i Rezerwaty Przyrody 23(1): 3-12.

Kukwa M. 2005a. Lecanora thysanophora (Lecanoraceae, zlichenizowane Ascomycota) w Polsce. - Fragmenta Floristica et Geobotanica Polonica 12(2): 385-391.

KUKWA M. 2005b. New or interesting records of lichenicolous fungi from Poland III. - Herzogia 18: $37-46$.

KuKWA M. 2006. Notes on taxonomy and distribution of the lichen species Lepraria ecorticata comb. nov. - Mycotaxon 97: 63-66.

Kukwa M. 2009. The lichen genus Ochrolechia in Poland III with a key, and notes on some taxa. - Herzogia 22: 43-66. 
KuKwa M. 2011. The lichen genus Ochrolechia in Europe, s. 309. Fundacja Rozwoju Uniwersytetu Gdańskiego, Gdańsk.

Kunwa M. \& CZarnota P. 2006. New or interesting records of lichenicolous fungi from Poland IV. - Herzogia 19: 111-123.

KuKwa M. \& Diederich P. 2005. Monodictys epilepraria, a new species of lichenicolous hyphomycetes on Lepraria. - Lichenologist 37(3): 217-220.

KuKWa M. \& Flakus A. 2009. New or interesting records of lichenicolous fungi from Poland VII. Species mainly from Tatra Mountains. - Herzogia 22: 191-211.

KuKwa M. \& JABŁoŃSKA A. 2008. New or interesting records of lichenicolous fungi from Poland VI. - Herzogia 21: 167-179.

KuKWA M. \& JabŁońsKA A. 2009. New records of two crustose sorediate lichens from central Europe. - Mycotaxon 107: 375-381.

Kunwa M. \& Kowalewska A. 2007. New or interesting records of lichenicolous fungi from Poland V. Species mainly on Cladonia. - Herzogia 20: 199-207.

Kukwa M. \& Kubiak D. 2007. Six sorediate crustose lichens new to Poland. - Mycotaxon 102: 155-164.

Kunwa M., Czarnota P. \& Łubek A. 2017. Three lichen species in Buellia, Catillaria, and Cheiromycina, new to Poland. - Mycotaxon 132: 177-182.

Kunwa M., Czarnota P. \& Perz P. 2010. New or interesting records of lichenicolous fungi from Poland VIII. - Herzogia 23(1): 111-119.

Kunwa M., Pietnoczko M. \& Czyżewska K. 2012. The lichen family Parmeliaceae in Poland. II. The genus Cetrelia. - Acta Societatis Botanicorum Poloniae 81(1): 43-52.

Kukwa M., Szymczyk R. \& Kowalewska A. 2013. New or interesting records of lichenicolous fungi from Poland IX. - Herzogia 26(1): 159-168.

Launis A., Pykälä J., van den Boom P., Sérusiaux E. \& Myllys L. 2019. Four new epiphytic species in the Micarea prasina group from Europe. - Lichenologist 51(1): 7-25.

LisickÁ E. 2005. The lichens of the Tatry Mountains, s. 439. VEDA, Slovak Academy of Sciences, Bratislava.

MatuRa N. 2016. Nowe stanowiska rzadkich gatunków porostów w Tatrach Polskich. - Fragmenta Floristica et Geobotanica Polonica 23(2): 26-27.

Matura N. 2020. Porosty w dolinach potoków polskich Karpat Zachodnich, s. 166. Instytut Botaniki im. W. Szafera, Polska Akademia Nauk, Kraków.

MatuRA N. \& KRZEWicka B. 2015. Verrucaria species and other rare amphibious lichens in the Beskid Sądecki Mts. - Acta Mycologica 50(1): 1057.

Matura N., Krzewicka B. \& Flakus A. 2017. Seven species of freshwater lichen-forming fungi newly recorded from Poland. - Polish Botanical Journal 62(2): 273-278.

MAtwiEJuk A. 2011. Rhizocarpon timdalii (Rhizocarpaceae, lichenized Ascomycota), a species new to Poland. - Polish Botanical Journal 56(1): 125-126.

MiądLIKowsKa J. 1999. Rodzaj Peltigera (Peltigerales, Ascomycota) na tle jego współczesnej systematyki. Praca doktorska, Katedra Ekologii Roślin i Ochrony Przyrody, Uniwersytet Gdański, Gdańsk.

MiądLIKowsKa J. \& Alstrup V. 1995. Some peltigericolous fungi and lichens mainly from Poland. - Graphis Scripta 7(1): 7-10.

Millanes A. M., Diederich P., Westberg M. \& Wedin M. 2016. Three new species in the Biatoropsis usnearum complex. - Herzogia 29: 337-354. 
MотүKa J. 1927. Materiały do flory porostów Tatr. Część II. - Sprawozdanie Komisji Fizyjograficznej PAU w Krakowie 61: 1-16.

MycoBank Fungal Databases, Nomenclature \& Species Banks. http://www.mycobank.org (dostęp: 09.2020).

NowaK J. 1974. Materiały do flory porostów Tatr polskich. - Fragmenta Floristica et Geobotanica 20(1): 89-102.

NowaK J. 1998a. Porosty Beskidów Wyspowego i Żywieckiego, Pasma Jałowca i Masywu Babiej Góry. - Monographiae Botanicae 83: 3-131.

NowAK J. 1998b. Porosty (Lichenes). 6(2). Buelliaceae (Physciaceae sensu lato). - W: Rośliny zarodnikowe Polski i ziem ościennych, s. $236+26$ pls. Instytut Botaniki im. Szafera, Polska Akademia Nauk, Kraków.

OLECH M. 1973. Porosty Beskidu Sądeckiego. - Zeszyty Naukowe Uniwersytetu Jagiellońskiego, Prace Botaniczne 1: 87-192.

Olech M. 2004. Lichens of the Tatra National Park. A checklist. - W: Z. MireK \& M. RoniKIER (red.), Biodiversity of the Tatra National Park 2: 1-137. W. Szafer Institute of Botany, Polish Academy of Sciences, Kraków.

OsET M. 2014. The lichen genus Stereocaulon (Schreb.) Hoffm. in Poland - a taxonomic and ecological study. - Monographiae Botanicae 104: 1-81.

Oset M. \& Kunwa M. 2010. The lichen genus Pertusaria in Poland I. P. multipuncta and P. ophthalmiza. - Acta Mycologica 45(2): 231-238.

Ossowska E. \& Kukwa M. 2016. Parmelia barrenoae and P. pinnatifida, two lichen species new to Poland. - Herzogia 29(1): 198-203.

Ossowska E., Szymczyk R., Bohdan A. \& Kukwa M. 2014. The lichen family Parmeliaceae in Poland. III. Parmelia serrana, new to Poland. - Acta Societatis Botanicorum Poloniae 83(1): 81-84.

OsYCZKA P. 2006. Cladonia borealis (Cladoniaceae, lichenized Ascomycota) in the Polish Carpathians. - Polish Botanical Journal 51(2): 230-232.

OsyczKa P. 2011. The genus Cladonia, group Cocciferae, in Poland. - Herzogia 24(2): 231-249.

OsyczKa P. 2012. The lichens of Cladonia, 'supergroup' Perviae, in Poland. - Herzogia 25(1): 15-30.

OsYczka P. \& KościelniaK R. 2009. Cladonia metacorallifera, a lichen species new to the Eastern Carpathians. - Acta Mycologica 44(2): 233-238.

Osyczka P., Węgrzyn M. \& Flakus A. 2006. Two species of the genus Cladonia (Cladoniaceae, lichenized Ascomycota) new to the Polish Tatra Mts. - Polish Botanical Journal 51(2): 233-235.

ReHman A. 1879. Systematyczny przegląd porostów znalezionych dotąd w Galicyi Zachodniej opracowany na podstawie własnych i cudzych spostrzeżeń. - Sprawozdanie Komisyi Fizyjograficznej AU w Krakowie 13: 3-66.

RouPPERT K. 1912. Grzyby zebrane w Tatrach, Beskidzie Zachodnim i na Pogórzu. - Sprawozdanie Komisyi Fizjograficznej AU w Krakowie 46: 80-100.

RYDZAK J. 1955. Wpływ małych miast na florę porostów. Cz. II. Beskidy Zachodnie. Wisła, Ustroń, Muszyna, Iwonicz, Rymanów, Lesko. - Annales Universitatis Mariae Curie-Skłodowska, Sectio C 10: $33-66$.

StaRmachowa B. \& KiszKa J. 1965. Grzyby pasożytnicze występujące na porostach zebranych w Beskidzie Śląskim (Karpaty Zachodnie). - Fragmenta Floristica et Geobotanica 11(4): 631-637.

STOLARCZYK P. 2009. Materiały do bioty porostów Dołów Jasielsko-Sanockich (Karpaty Zachodnie). - Fragmenta Floristica et Geobotanica Polonica 16(1): 87-126. 
SzCZePańsKa K. \& Kossowska M. 2014. The lichen-forming fungi of the Xanthoparmelia pulla group (Parmeliaceae, Ascomycota) in Poland. - Acta Societatis Botanicorum Poloniae 83(1): 59-65.

SzCZEPAŃSKA K. \& KossowsKa M. 2017. Cetrariella commixta and the genus Melanelia (Parmeliaceae, Ascomycota) in Poland. - Herzogia 30(1): 272-288.

ŚLIWA L. 2006. Additions to the lichen flora of the Tatry National Park and its surroundings (Polish Carpathians). - W: A. Lackovičová, A. GutTovÁ, E. LisickÁ \& P. Lizoň (red.), Central European lichens. Diversity and threat, s. 305-313. Mycotaxon, Ltd. Ithaca.

ŚLIWA L. 2009. Lecanora semipallida (lichenized Ascomycota) in Poland. - Polish Botanical Journal 54(1): 31-36.

Śliwa L. 2010. Contribution to the lichen biota of the Pogórze Wiśnickie foothils (Carpathians). - Acta Mycologica 45(2): 219-230.

ŚliWA L. \& FlakUS A. 2011. Lecanora microloba, a new saxicolous species from Poland. - Lichenologist 43(1): $1-6$.

Śliwa L. \& KRZEWICKA B. 2012a. Challenges of saxicolous lichens conservation - a case study of the Carpathians foothills. - W: L. LIPNICKI (red.), Lichen protection - Protected lichen species, s. 107-117. Wydawnictwo Sonar Literacki, Gorzów Wielkopolski.

Śliwa L. \& KRzewicka B. 2012b. New records of pyrenocarpous crustose lichens in the Polish Tatra Mts and surroundings. - Polish Botanical Journal 57(2): 463-471.

Śliwa L. \& Kukwa M. 2008. Calicium pinastri (lichenized Ascomycota), a lichen species new to Poland. - Polish Botanical Journal 53(2): 189-191.

Śliwa L. \& Kukwa M. 2012. New distribution data for sterile crustose lichens in the Polish Tatra Mts. - Polish Botanical Journal 57(1): 259-278.

Śliwa L. \& Matura N. 2018. Cladonia strepsilis (Cladoniaceae) i inne interesujące gatunki porostów w Polskich Karpatach. - Fragmenta Floristica et Geobotanica Polonica 25(2): 243-258.

Thüs H., Orange A., Gueidan C., Pykälä J., Ruberti C., Lo Schiavo F. \& Nascimbene J. 2015. Revision of the Verrucaria elaeomelaena species complex and morphologically similar freshwater lichens (Verrucariaceae, Ascomycota). - Phytotaxa 197: 161-185.

Tobolewski Z. 1958. Porosty Pienin. - Prace Komisji Biologicznej Poznańskiego Towarzystwa Przyjaciół Nauk 17(5): 1-124.

Tobolewski Z. 1959. Materiały do flory porostów Tatr III. - Prace Komisji Biologicznej Poznańskiego Towarzystwa Przyjaciół Nauk 21(1): 1-20.

Tobolewski Z. 1965. Wykaz porostów dotychczas stwierdzonych w Polsce (wraz z bibliografią lichenologiczną). - Prace Komisji Biologicznej Poznańskiego Towarzystwa Przyjaciół Nauk 24(3): 1-62.

ToBolewski Z. 1969. Materiały do flory porostów Tatr VI. - Prace Komisji Biologicznej Poznańskiego Towarzystwa Przyjaciół Nauk 24(6): 3-23.

WĘGRZYN M. 2004. Porosty epifityczne, epiksyliczne i epigeiczne piętra kosodrzewiny na Babiej Górze. - Fragmenta Floristica et Geobotanica Polonica 11(2): 355-363.

WęgrZYN M. 2008. New record of lichens and lichenicolous fungi from the Polish Tatra Mountains. - Polish Botanical Journal 53(2): 163-168.

WęGRZYN M. 2009. Porosty piętra kosodrzewiny w polskiej części Tatr Wysokich. s. 117. Instytut Botaniki im. W. Szafera, Polska Akademia Nauk, Kraków.

WieCZOREK A. 2018. The lichen genus Opegrapha s.1. in Poland: morphological variability, ecology, and distribution. - Monographiae Botanicae 107: 3-162.

WILK K. 2006. Diplotomma scheideggerianum (Lecanorales, Ascomycota), a lichenicolous lichen new to Poland. - Polish Botanical Journal 51(2): 228-229. 
WILK K. 2011. New or noteworthy records of Caloplaca (Teloschistaceae) from Poland. - Mycotaxon 115: 83-98.

WILK K. 2012. Calcicolous species of the genus Caloplaca in the Polish Western Carpathians. - Polish Botanical Studies 29: 1-91.

WILK K. 2015. Four species of Caloplaca s.l. (lichenized Ascomycota, Teloschistaceae) new for Poland. - Polish Botanical Journal 60(2): 197-201.

Wilk K. \& Flakus A. 2006. Four species of Caloplaca (Teloschistaceae, lichenized Ascomycota) new to Poland. - Mycotaxon 96: 61-71.

WILK K. \& ŚLIWA L. 2012. Note on Caloplaca soralifera (Teloschistaceae, lichenized Asomycota), a lichen species new to Poland. - Acta Societatis Botanicorum Poloniae 81(1): 61-63.

Wojewoda W. 2003. Checklist of Polish larger Basidiomycetes. s. 812. W. Szafer Institute of Botany, Polish Academy of Sciences, Kraków.

ZDUŃCZYK A. \& KuKWA M. 2012. Revised distribution of the lichen species Haematomma ochroleucum in Poland. - Polish Botanical Journal 57(2): 473-477.

ZDUŃCZYK A. \& KuKWA M. 2014. A revision of sorediate crustose lichens containing usnic acid and chlorinated xanthones in Poland. - Herzogia 27(1): 13-40.

Zhurbenko M. P. 2013. Lichenicolous fungi and some allied lichens from the Canadian Arctic. - Opuscula Philolichenum 12: 180-197.

\section{SUMMARY}

Since the publication of the first checklists of lichen taxa from the Polish Carpathians (BIELCZYK 2003; KoŚCIELNIAK \& KisZKa 2003, 2005; KondratyUK et al. 2003; BielCZYK et al. 2004; OleCH 2004; LisickÁ 2005), lichenological knowledge about this area has grown significantly. Recent intensive field inventories, taxonomic studies, and advances in methods and techniques used in species identification have yielded much new data to the lichen biota of the Polish Carpathians, resulting in an updated checklist comprising 1571 taxa, including 1524 species, 19 subspecies and 28 varieties. In this paper we present only 241 lichen species, 108 lichenicolous fungi and two lichenicolous myxomycetes that were reported from the Polish Carpathians after 2003 and not in those first checklist editions (BIELCZYK 2003; KoŚCIELNIAK \& KISZKA 2003). For each taxon, its distribution in individual ranges of the Carpathians are given in accordance with the regionalization proposed by KONDRACKI (1989), with reference to bibliographic sources. A separate list includes species that should be excluded from the list of Polish Carpathian lichens. The list of literature supplements the lichenological bibliography of the Polish Carpathians compiled in the study by BIELCZYK (red.) (2003).

Wptynęto: 20.10.2020 r.; przyjęto do druku: 07.12.2020 r. 